\title{
Lo incierto de los programas de beneficios por colaboración
}

\author{
The Uncertainty of Cooperation \\ Benefit Programs
}

O incerto dos programas de beneficios por colaboración

Diana Carolina Gómez Ortiz

https://orcid.org/0000-0001-6497-6705. Superintendencia de Industria y Comercio, Colombia.c.dgomez@sic.gov.co, gomezo.diana@hotmail.com

Recibido: 06/07/2020. Envío a pares: 14/09/2020 Aprobado por pares: 29/09/2020. Aceptado: 03/04/2021

DOI: $10.5294 /$ dika.2021.30.1.2

Para citar este artículo / To reference this article / Para citar este artigo 


\section{Resumen}

Este trabajo desarrolla de manera reflexiva la rivalidad entre la política criminal y los programas de clemencia en el derecho de la competencia. Con la expedición del estatuto anticorrupción colombiano se introdujo la práctica anticompetitiva conocida como colusión en licitaciones públicas en la legislación de competencia como una conducta penal. Esta política criminal tenía como finalidad sancionar más severamente las prácticas restrictivas de la competencia que afectan la contratación pública y, a la vez, desincentivar su ocurrencia. Sin embargo, el resultado pudo no ser el esperado. La penalización entró en disputa con los programas de clemencia previstos en la legislación de competencia. A través de los programas de beneficios por colaboración, el legislador otorgó concesiones que incluso preveían la exoneración total de las multas para aquellas personas que delataran conductas anticompetitivas, a cambio de entregar información útil para la autoridad. Sin embargo, al momento de definir el programa de clemencia, el legislador no había previsto la posibilidad de que conductas restrictivas de la competencia pudieran ser sancionadas a través de sistemas jurídicos como el penal. Esta desconexión entre la política criminal y los beneficios por colaboración habría desincentivado la participación de las personas en los programas que otorgaban estos beneficios. Debido a esta situación, este documento tiene como propósito analizar la efectividad de los programas de beneficios por colaboración en Colombia ofrecidos por la Superintendencia de Industria y Comercio de cara a la tipificación de la colusión como un delito.

\section{Palabras clave}

Programas de beneficios por colaboración; amnistía; delación; prácticas restrictivas de la competencia; carteles; colusión en contratación pública. 


\section{Abstract}

This paper reflects on the rivalry between criminal policy and leniency programs in competition law. The issuance of the Colombian anti-corruption code introduced the anti-competitive practice known as collusion in public procurement into competition law as a crime. This criminal policy aimed to punish more severely restrictive competition practices that adversely affect public procurement while discouraging their occurrence; however, it did not turn out as planned. The punishment conflicted with the leniency programs provided for in competition law. Through collaboration benefit programs, the legislator granted benefits such as the exemption of fines for those who reported anti-competitive conduct in exchange for information helpful to the authority. Nevertheless, when defining the leniency program, the legislator had not anticipated the possibility that restrictive competition conduct could be penalized by legal systems such as the criminal one. This disconnection between criminal policy and cooperation benefits would have discouraged people's participation in cooperation benefit programs. Therefore, this article discusses the effectiveness of Colombian cooperation benefit programs offered by the Superintendence of Industry and Commerce regarding the classification of collusion as a crime.

\section{Keywords}

Cooperation benefit programs; amnesty; accusation; restrictive competition practices; cartels; collusion in public procurement. 


\section{Resumo}

Este trabalho desenvolve, de maneira reflexiva, a rivalidade entre a política criminal e os programas de clemência no direito da concorrência. Com a expedição do estatuto anticorrupção colombiano, foi introduzida a prática anticoncorrencial conhecida como "conluio em licitações públicas" na legislação de concorrência como uma conduta penal. Essa política criminal tinha como finalidade sancionar mais gravemente as práticas restritivas da concorrência que afetam a contratação pública e, por sua vez, desincentivar sua ocorrência. Contudo, o resultado pôde não ter sido o esperado. A penalização entrou em disputa com os programas de clemência previstos na legislação de concorrência. A partir dos programas de beneficios por colaboración (delações premiadas), o legislador outorgou benefícios que inclusive previam a exoneração total das multas para as pessoas que delatassem condutas anticoncorrenciais em troca de fornecer informações úteis para a autoridade. No entanto, no momento de definir o programa de clemência, o legislador não tinha previsto a possibilidade de que condutas restritivas da concorrência pudessem ser sancionadas por meio de sistemas jurídicos como o penal. Essa desconexão entre a política criminosa e os benefícios por colaboração teria desincentivado a participação das pessoas nos programas de beneficios por colaboración. Tendo em vista essa situação, este documento tem o objetivo de analisar a efetividade dos programas de beneficios por colaboración na Colômbia oferecidos pela Superintendência da Indústria e do Comércio em face da tipificação do conluio como um delito.

\section{Palavras-chave}

Programas de beneficios por colaboración; anistia; práticas restritivas da concorrência; cartéis; colusão em contratação pública. 
Sumario: Introducción. 1. Generalidades de los programas de beneficios por colaboración. 1.1. Los beneficios de colaboración en Colombia y las sanciones administrativas por prácticas restrictivas de la competencia. 2. El fortalecimiento de las sanciones por acuerdos restrictivos de la competencia y la exoneración total o parcial de la sanción por imponer a través del acceso a los programas de beneficios por colaboración. 2.1. Las conductas anticompetitivas criminalizadas en Estados Unidos, Chile, México y Brasil, y su tratamiento a través del acceso a los programas de beneficios por colaboración. 2.2. La criminalización de la colusión en contratación pública en Colombia. 3. La experiencia colombiana: comparación de la implementación del programa de clemencia en las investigaciones por colusión en contratación pública versus las demás prácticas restrictivas de la competencia. 4. Conclusiones. Referencias. Anexo 1. Datos de las investigaciones en procesos de contratación estatal (Colusión). Anexo 2. Datos de las investigaciones sobre acuerdos restrictivos de la competencia en el mercado en general.

\section{Introducción}

Las cuestiones legales y las morales no son en absoluto las mismas, pero guardan cierta afinidad entre sí porque unas y otras presuponen la capacidad de juzgar. ${ }^{1}$

Los programas de beneficios por colaboración han sido implementados como una estrategia para erradicar los carteles empresariales en los mercados. A través de ellos, las personas naturales o jurídicas que se encuentran incursas en conductas anticompetitivas pueden obtener la exoneración total o parcial de las sanciones por imponer, al colaborar con la autoridad de competencia.

Bajo la existencia de estos programas o convenios de beneficios por colaboración, se busca asegurar una racionalidad económica que propende por obtener una mayor eficiencia y eficacia en las investigaciones que adelanta la autoridad de competencia. No obstante lo anterior, debe tenerse en cuenta que los incentivos para colaborar con la justicia deben resultar lo suficientemente atractivos para que las personas que se encuentran incursas en prácticas anticompetitivas prefieran aceptar la comisión de una conducta ilegal -y aportar los elementos de prueba suficientes- a cambio de ser exoneradas total o parcialmente de la sanción. De lo contrario, estas personas podrían verse atraídas por continuar inmersas en conductas anticompetitivas, al representarles un mayor beneficio. Por esta razón, resulta importante analizar si la introducción de sanciones de índole penal sobre conductas investigadas por la autoridad de competencia pueden resultar adversas a los incentivos por colaboración que ofrecen los programas de clemencia por conductas anticompetitivas. El presente escrito tiene como propósito estudiar la repercusión que ha tenido la

1 Hanna Arendt, "Responsabilidad personal bajo una dictadura”, en H. Arendt, Responsabilidad y juicio, Barcelona, Paidós Básica, trad. M. Candel, 2007, p. 53. 
introducción de la colusión como un tipo penal -en el que solamente se ofrece la atenuación de la sanción por imponer mas no su exoneración-sobre la efectividad de la figura de los programas de beneficios por colaboración que ofrece la Superintendencia de Industria y Comercio por la comisión de conductas anticompetitivas.

Con el fin de abordar el tema propuesto, se hará una precisión conceptual sobre lo que la literatura especializada ha entendido por colusión:

\begin{abstract}
La colusión es un acuerdo que, independientemente de la forma en que se constituya, es celebrado entre personas que tienen el deber de competir en caso de que concurran en un proceso de contratación pública. Ese acuerdo está orientado a suprimir la rivalidad entre sus integrantes de manera tal que resulte idóneo para reducir las presiones competitivas en el contexto del proceso de contratación pública sobre el cual verse, esto es, para incrementar la probabilidad de victoria de alguna de las personas participantes en el acuerdo o para alterar cualquiera de las condiciones de competencia del proceso en beneficio de los colusores. ${ }^{2}$
\end{abstract}

Para abordar el tema propuesto, este artículo se dividirá en tres apartados. En primer lugar, se presentarán algunas precisiones teóricas sobre los propósitos generales de los programas de clemencia y su introducción en la legislación colombiana. En segundo lugar, se expondrá cómo el fortalecimiento de las sanciones y el aumento de los beneficios por colaboración han sido entendidos como mecanismos que incrementan el costo de las conductas anticompetitivas e incentivan las solicitudes de acceso a los programas de clemencia. Para el efecto, se hará un paralelo entre los países del continente americano en los que se han tipificado como delito conductas restrictivas de la competencia. En tercer lugar, se analizará la efectividad que han tenido los programas de beneficios por colaboración ofrecidos por la Superintendencia de Industria y Comercio en Colombia. Este análisis parte de un paralelo entre la implementación del programa de clemencia en las investigaciones por colusión versus las investigaciones por prácticas restrictivas de la competencia en el mercado en general que adelanta la autoridad de competencia. Con esto, se pretende evidenciar que la falta de armonización entre la política criminal y las figuras introducidas para la protección de la competencia han desincentivado las solicitudes de acceso al programa de beneficios por colaboración que es ofrecido por la Superintendencia de Industria y Comercio, al incluir como delitos conductas anticompetitivas sin los incentivos suficientes para delatar.

2 María Catalina Gastelbondo Chiriví y Francisco Melo Rodríguez, “La colusión: entre las fórmulas verbales y nómica: reflexiones sobre los diez años de la Ley 1340 de 2009, Bogotá, Universidad Externado de Colombia, 2019, pp. 141-179, en https://bdigital.uexternado.edu.co/bitstream/001/2763/1/MGA-spa-2019-La_colusion_entre_ las_formulas_verbales_y_la_realidad_dinamica 


\section{Generalidades de los programas de beneficios de colaboración}

Los programas de beneficios por colaboración adoptados en los regímenes de protección de la libre competencia económica corresponden a una institución implementada para combatir los carteles empresariales. ${ }^{3}$ A través de esta herramienta, los infractores de las normas para la protección de la competencia económica pueden obtener una exoneración total o parcial de la sanción que, de otra forma, les sería impuesta. A cambio de ello, el delator debe ofrecer a la autoridad de competencia información y pruebas útiles que le permitan perseguir el cartel anticompetitivo de una manera eficaz y eficiente.

Uno de los propósitos fundamentales de los programas de beneficios por colaboración es incrementar la efectividad de las investigaciones por infracciones al régimen de protección de la libre competencia económica. Esta efectividad se logra a través de la obtención de material probatorio que facilite la detección y sanción de carteles anticompetitivos. Por esta razón, los programas de clemencia se han convertido en una herramienta relevante para la aplicación efectiva de las normas para la protección de la competencia económica. ${ }^{4}$

Debe tenerse en cuenta que los acuerdos restrictivos de la competencia, tales como la fijación de precios, la manipulación de procesos de contratación estatal y la repartición de mercados -que han sido considerados como "la infracción más grave de las leyes de defensa de la competencia" ${ }^{5}$ - son generalmente de naturaleza secreta. ${ }^{6}$ Por esta razón, para la autoridad de competencia resulta una labor ardua y costosa al momento de investigar y detectar carteles empresariales en los mercados.

A pesar de que las autoridades de competencia cuenten con la habilitación legal de: i) recaudar información conducente para verificar el cumplimiento de las normas de competencia, tales como libros y papeles de comercio, docu-

3 Donald I. Baker, "The use of criminal law remedies to deter and punish cartels and bid-rigging", Geo. Wash. L. Rev. 69 (2001), p. 693.

4 Organization for Economic Co-operation and Development (OECD), Use of Markers in Leniency Programmes, Note by the Secretariat, 2019, DAF/COMP/WP3(2014)9, en http://www.oecd.org/officialdocuments/publicdis playdocumentpdf/?cote=DAF/COMP/WP3(2014)9\&doclanguage=en

5 Organization for Economic Co-operation and Development (OECD), Recommendation of the Council concerning Effective Action against Hard Core Cartels, OECD/LEGAL/0452, 2019, en https://legalinstruments. oecd.org/en/instruments/OECD-LEGAL-0452. En el mismo sentido, Aldo González, La delación compensada o amnistía en la lucha anti-carteles, Chile, 2007, en http://econ.uchile.cl/public/Archivos/pub/8ca92c23-e188-4d469845-306999ffc174.pdf, afirma que: “La cartelización es considerada la ofensa de mayor gravedad en casi la totalidad de las legislaciones sobre competencia alrededor del mundo. El primer hito de la legislación anticarteles a nivel mundial es la promulgación en 1890 del 'Sherman Act' de Estados Unidos, cuyo propósito fue declarar ilegales a los carteles o 'trusts' -por lo que en inglés se habla de legislación anti-trust- que hasta la fecha opera abiertamente".

6 Álvaro Yáñez Rueda, "Balance y desafíos del programa de clemencia en Colombia”, en A. M. García Pabón, A. M. Pérez Herrán y I. Beltrán Prado (eds.), Competencia económica: reflexiones sobre los diez años de la Ley 1340 de 2009, Bogotá, Universidad Externado de Colombia, 2019, pp. 181-207. 
mentos, correos electrónicos y demás documentos privados que den cuenta de la actividad comercial de los agentes del mercado; ${ }^{7}$ ii) adelantar declaraciones útiles para el esclarecimiento de los hechos investigados; ${ }^{8} \mathrm{y}$, iii) realizar visitas administrativas de inspección, incluso sin control judicial previo como en el caso colombiano, ${ }^{9}$ es usual que los integrantes de un cartel anticompetitivo oculten información, utilicen códigos secretos y den una apariencia de legalidad a su conducta a fin de que esta no pueda ser detectada.

Por esta razón, la colaboración proporcionada por un informante dota a la autoridad de competencia de un conocimiento "desde adentro" del cartel que le permite, no solo i) poner en contexto los elementos de prueba recaudados por la autoridad hasta ese momento procesal, sino que, adicionalmente, le permite ii) entender el funcionamiento del cartel y iii) obtener pruebas contundentes que den cuenta del comportamiento ilegal.

De allí que los programas de beneficios por colaboración se hayan convertido, para las autoridades de competencia, en un instrumento determinante al momento de dar aplicación efectiva a las normas que protegen la libre competencia económica. No puede perderse de vista que los acuerdos restrictivos de la competencia no solo perjudican a los consumidores a través del incremento de precios, la reducción de la producción y calidad de bienes y servicios, sino que, adicionalmente, también privan a la economía del dinamismo y la innovación que producen las presiones competitivas. ${ }^{10}$ Por lo anterior, optimizar

$7 \quad$ En la legislación colombiana, el numeral 63 del artículo 1 del Decreto 4886 de 2016 faculta a la Superintendencia de Industria y Comercio para solicitar a personas naturales y jurídicas el suministro de datos, informes, libros y papeles de comercio que se requieran para el correcto ejercicio de sus funciones. Esta posición ha sido sostenida por la Superintendencia de Industria y Comercio en distintos actos administrativos como en la Resolución 71843 del 9 de diciembre de 2019 (Rad. 17-335942), posición que ha sido avalada por la Corte Constitucional en Sentencia C-165 de 2019, M. P. Alejandro Linares Cantillo, Expediente D-12536, 10 de abril de 2019. La legislación mexicana, en los artículos 12, 73, 75, 94 y 119 de la Ley Federal de Competencia, también permite requerir la exhibición de papeles, libros, documentos, archivos e información generada por medios electrónicos, ópticos o de cualquier otra tecnología, a fin de comprobar el cumplimiento de esta Ley. En el mismo sentido el literal c, del numeral la legislación peruana faculta a la Secretaría Técnica para que solicite la exhibición de todo tipo de documentos, incluyendo los libros contables y societarios, los comprobantes de pago, la correspondencia interna o externa y los registros magnéticos o electrónicos incluyendo los programas que fueran necesarios para su lectura. Por su parte, la legislación chilena también prevé en el numeral $\mathrm{h}$ del artículo 39 del Decreto 211 de 2016, que la Fiscalía Nacional Económica puede solicitar a los particulares información y antecedentes que estime necesarios en el marco de las investigaciones que adelante.

8 Como sucede, entre otros, en el caso chileno (num. j, art. 39, DL 211 de 2016), en el caso colombiano (num. 64, art. 1, Dc. 4886 de 2011), en el caso mexicano (arts. 12, 73, 75, 94 y 119, Ley Federal de Competencia), en el caso peruano (lit. c, num, 15.3., artículo 15, DS 030 de 2010).

9 De acuerdo con el numeral 62 del artículo 1 del Decreto 4886 de 2011, la Superintendencia de Industria y Comercio colombiana puede realizar visitas administrativas de inspección, decretar y practicar pruebas y recaudar toda la información conducente, con el fin de verificar el cumplimiento de las disposiciones legales cuyo control le compete, y adoptar las medidas que correspondan conforme a la ley. En el mismo sentido, la legislación mexicana también permite a la Autoridad Investigadora realizar visitas de verificación con el fin de obtener datos y documentos que se relacionen con la investigación. Por su parte, en el caso chileno, la Fiscalía Nacional Económica está facultada para hacerlo, sin embargo, debe contar con aprobación del Tribunal de Defensa de la Libre Competencia y con autorización del Mministro de la Corte de Apelaciones de Santiago.

10 Superintendencia de Industria y Comercio, Informe Motivado, Caso “PAE Frutas”, Rad. 17-292981, 2018; Organization for Economic Co-operation and Development (OECD), Ficha informativa sobre los efectos macroeconómicos de la política de competencia, 2014, en https://www.oecd.org/daf/competition/2014-competitionfactsheet-print-es.pdf 
el diseño de las políticas de clemencia es un objetivo clave para las autoridades de competencia -y para la sociedad en general- al momento de detectar y reprimir conductas anticompetitivas en favor de la economía de los países y del aumento positivo de la productividad. ${ }^{11}$

En lo que respecta a América Latina, a pesar de que los programas de beneficios por colaboración son más bien recientes, pues la mayoría datan del año 2000 al 2009,12 se ha reflejado en una mejora en el desarrollo de los procesos investigativos al permitir la detección y posterior sanción de carteles dentro de los distintos escenarios de mercado. ${ }^{13}$ Esto se basa en que los programas de beneficios por colaboración generan un efecto disuasorio al desincentivar, por un lado, la formación de carteles empresariales y, por el otro, desestabilizar el equilibrio de los carteles que se encuentran en funcionamiento a través del rompimiento de lealtades existentes entre sus integrantes. ${ }^{14}$ La explicación de esta consecuencia ha sido evidenciada ya por la Organización para la Cooperación y el Desarrollo Económicos (OCDE): “Los miembros de un cartel saben que, en cualquier momento, cualquiera de sus participantes, puede proporcionar al organismo de competencia información sobre la existencia del cartel, sus miembros, su naturaleza, su ámbito de actuación y su duración". ${ }^{15}$

No obstante lo anterior, los programas de clemencia no surten efecto hasta que las autoridades de competencia no imponen sanciones a los carteles anticompetitivos que resulten realmente ejemplarizantes. ${ }^{16}$ De esta manera, si las sanciones que se imponen no son significativas y la autoridad de competencia no proyecta una imagen de efectividad, los integrantes de un cartel no se verían incentivados para suscribir un convenio de beneficios por colaboración. ${ }^{17}$ Por

11 Catarina M. P. Marvão y Giancarlo Spagnolo, "What Do We Know About the Effectiveness of Leniency Policies? A Survey of the Empirical and Experimental Evidence" (Mimeo), 2014, en https://ssrn.com/abstract $=2511613$

12 Con excepción de Perú (Programa de Clemencia) que data del año 1996, los demás países, incluyendo a Brasil (Programa de Clemencia), Chile (Programa de Delación Compensada), Colombia (Programa de Beneficios por Colaboración), Ecuador (Programa de Clemencia), El Salvador (Programa de Clemencia), México (Programa de Inmunidad y Reducción de Sanciones), Panamá (Programa de Beneficios de Dispensación o Disminución de Sanciones) y Uruguay (Programas de Clemencia) implementaron los programas de beneficios por colaboración entre los años 2000 al 2009.

13 Organization for Economic Co-operation and Development (OECD), Paper by the secretariat Felipe Serrano. Leniency programmes in Latin America and the Caribbean: Recent experiences and lessons learned, OECD 14th Latin American and Caribbean Competition Forum, Mexico City, Mexico. 2016, en https://one.oecd.org/ document/DAF/COMP/LACF(2016)5/en/pdf

14 Cfr. Organization for Economic Co-operation and Development (OECD), Derecho y política de la competencia en Colombia. Examen inter-pares 2009, en https://www.oecd.org/countries/colombia/44111213.pdf; Superintendencia de Industria y Comercio, Informe Motivado, Caso “Papeles Suaves”, Rad. 14-151027, 2016; Superintendencia de Industria y Comercio, Resolución 59363, Rad. 17-329492, 20 de septiembre de 2017.

15 Organization for Economic Co-operation and Development (OECD), Paper by the secretariat Felipe Serrano, op. cit.

16 Organization for Economic Co-operation and Development (OECD), (2002), Fighting Hard-core Cartels: Harm, Effective Sanctions and Leniency Programmes, OECD Publishing, Paris, 2002, en https://www.oecd-ilibrary.org/ governance/fighting-hard-core-cartels_9789264174993-en

17 "La necesidad imperante de contemplar en nuestra normativa multas severas para evitar que los agentes asuman una sanción como parte de su acuerdo anticompetitivo y estén en capacidad de pagarla sin que se alteren las ganancias provenientes del cártel" (Juliana Molina Gómez, Hacia la implementación de un programa 
esta razón, la significatividad de las sanciones por imponer y la alta probabilidad de ser detectado y sancionado, sumado a la existencia de una posibilidad de reducción de la sanción, son un incentivo importante al momento de acogerse a un programa de clemencia como herramienta para la lucha contra los carteles empresariales. ${ }^{18}$

\subsection{Los beneficios por colaboración en Colombia y las sanciones administrativas por prácticas restrictivas de la libre competencia económica}

En el caso colombiano, los programas de beneficios por colaboración también están concebidos como un mecanismo que procura la detección y represión de prácticas restrictivas de la competencia. A través de la Ley 1340 de 2009, que actualizó el Régimen de Protección de la Libre Competencia Económica, se implementó la figura de los programas de beneficios por colaboración y se fortalecieron las sanciones administrativas que se debían imponer por prácticas restrictivas de la competencia.

En un primer momento de la reglamentación colombiana, el artículo 14 de la Ley 1340 de 2009 -por el cual se implementaron los programas de beneficios por colaboración- dejó abierto el desarrollo normativo de dicho precepto. Por ello, a través del Decreto 2896 de 2010 se establecieron las condiciones generales para conceder beneficios por colaboración como mecanismo para apoyar la detección y represión de acuerdos restrictivos de la libre competencia económica. Uno de los aspectos reglamentados fue la posibilidad de reducir las sanciones por imponer. En ese entonces, las reducciones por las que podía verse beneficiado el delator -contenidas en el artículo 13 del mencionado decreto-, eran mayores que aquellas que rigen actualmente. Al respecto, las personas que no cumplieran con los requisitos para solicitar la exoneración total de la sanción podían ser beneficiadas con una reducción de hasta el $70 \%$ de la multa, cuando cumplieran en primer lugar de marcaje con las condiciones establecidas en el artículo 11 del texto mencionado. Por su parte, la segunda persona que se acercara para acceder a los beneficios por colaboración podía verse beneficiada en hasta un $50 \%$ de la multa $y$, finalmente, la tercera persona y siguientes que lo sucedieran, y que se acogieran con posterioridad al programa de beneficios por colaboración, podían obtener una reducción de hasta un $30 \%$ de la sanción.

de clemencia en Colombia, Pontificia Universidad Javeriana, 2009, pp. 1-96, en https://repository.javeriana.edu. co/bitstream/handle/10554/16912/MolinaGomezJuliana2009.pdf?sequence=1\&isAllowed=y

18 Organization for Economic Co-operation and Development (OECD), Fighting Hard-core Cartels: Harm, Effective Sanctions and Leniency Programmes, op. cit. 
En un giro guiado por el fortalecimiento en la represión por la comisión de conductas anticompetitivas, el 16 de julio de 2015 se expidió el Decreto 1523 -modelo que actualmente rige en la legislación colombiana-. Uno de los cambios introducidos por el Decreto 1523 de $2015^{19}$ radicó en la incorporación de nuevos rangos en la reducción de la sanción. Dentro de este esquema, el delator que se encuentre en la primera posición de marcaje puede obtener la exoneración total de la multa por imponer. Mientras que el segundo solicitante puede verse beneficiado con una reducción entre el 30 al $50 \%$ de la multa. Por su parte, el tercer solicitante y siguientes pueden ser beneficiarios de una reducción en la sanción de hasta un $25 \% .^{20}$

De acuerdo con el artículo 2.2.2.29.1.1. del Decreto 1523 de 2015 vigente, los beneficios por colaboración se conceden a las personas naturales o jurídicas que "colaboren en la detección y represión" de acuerdos anticompetitivos. Para la consecución de esta finalidad, la colaboración que preste el informante en el marco de una investigación administrativa por infracciones al régimen de protección de la libre competencia económica debe proporcionar elementos de prueba que resulten útiles para determinar: i) la existencia del acuerdo, ii) su forma de operación, iii) sus principales actividades, iv) el nombre de los integrantes, v) su grado de participación, vi) producto o servicio sobre el que recae el acuerdo, vii) el área geográfica afectada y viii) la duración estimada del acuerdo que se investiga. ${ }^{21}$ Por esta razón, la celebración de un convenio de beneficios por colaboración se encuentra condicionado a que la información y las pruebas aportadas por el solicitante "agreguen valor" 22 a la investigación y a los elementos de prueba con los que ya cuenta la autoridad administrativa de competencia. La utilidad de la prueba debe ser determinada de acuerdo con la etapa en la que se encuentra la actuación administrativa. De allí que no se entienda como cumplida la carga a la que se enfrenta el solicitante cuando presenta información y elementos de prueba, si solamente se limi-

19 Decreto 1523 de 2015, por medio del cual se reglamenta el artículo 14 de la Ley 1340 de 2009 y se modifica el Capítulo 29 del Título 2 de la Parte 2 del Libro 2 del Decreto Único Reglamentario del Sector Comercio, Industria y Turismo; Decreto 1074 de 2015, sobre beneficios a las personas naturales y jurídicas que colaboren en la detección y represión de acuerdos restrictivos de la libre competencia, artículo 2.2.2.29.1.1 (Colombia).

20 Decreto 1523 de 2015, artículo 2.2.2.29.2.2: “Orden de prelación para la obtención de beneficios por colaboración. Los beneficios derivados de la firma del Convenio de Beneficios por Colaboración se otorgarán de conformidad con el momento en que el solicitante cumpla con los requisitos para marcar su entrada al Programa de Beneficios por Colaboración, en los términos del artículo 2.2.2.29.2.3. del presente decreto, de la siguiente manera: 1. Al primer solicitante se le otorgará la exoneración total de la multa. 2 . Al segundo solicitante se le otorgará una reducción de entre el treinta por ciento (30\%) y el cincuenta por ciento $(50 \%)$ de la multa a imponer, de acuerdo con la utilidad de la información y las pruebas aportadas en el trámite de la delación. 3. Al tercero y demás solicitantes posteriores se les otorgará una reducción de hasta el veinticinco por ciento $(25 \%)$ de la multa a imponer, de acuerdo con la utilidad de la información y las pruebas aportadas en el trámite. Se entenderá que la información o pruebas son útiles para la investigación, cuando agreguen valor respecto de aquellas con que ya cuenta la Superintendencia de Industria y Comercio, incluidas las aportadas por otros solicitantes o delatores. El grado de exigencia para determinar la utilidad de la información o las pruebas será valorado teniendo en cuenta la etapa en que se encuentre la actuación administrativa" (Colombia).

21 Decreto 1523/2015, op. cit.; Decreto 1074 de 2015, artículo 2.2.2.29.2.6. Requisitos para suscribir el Convenio de Beneficios por Colaboración, op. cit. (Colombia).

22 Decreto 1523/2015, op. cit.; Decreto 1074 de 2015, artículo 2.2.2.29.2.2. Orden de prelación para la obtención de beneficios por colaboración, op. cit. (Colombia). 
ta a i) corroborar los elementos de juicio con los que ya cuenta la autoridad administrativa, o a ii) confirmar los fundamentos fácticos de la imputación contenidos en la apertura de investigación. ${ }^{23}$

De otra manera no tendría sentido, en términos de costo-beneficio, que se conceda la exoneración total o parcial de la multa por imponer a un integrante del cartel por el solo hecho de presentar una solicitud de acceso al programa de beneficios por colaboración. Si este fuera el entendimiento, no se cumpliría el propósito de aplicar de forma más efectiva las normas para la protección de la competencia al momento de perseguir y sancionar los carteles empresariales. Pues, en todo caso, la autoridad de competencia tendría que desplegar los recursos necesarios para adelantar la investigación administrativa, obtener las pruebas necesarias y reprimir la conducta anticompetitiva.

Aunque la legislación colombiana actual permite la adhesión al programa de beneficios por colaboración tanto del primer solicitante como de aquellos solicitantes que se acerquen de manera posterior, ${ }^{24}$ no por esta razón el deber de acreditar la utilidad de la información y de las pruebas que debe certificar el informante para acceder al programa varía. ${ }^{25} \mathrm{El}$ grado de exigencia para determinar la utilidad de la información o de las pruebas allegadas al proceso, siempre será valorado al momento de presentar una solicitud de acceso al programa de clemencia. Por ello, cada solicitante debe acreditar los elementos de prueba que agregan valor a la investigación, como se mencionó, dependiendo de la fase en la cual se encuentre el proceso administrativo.

La importancia de exigir elementos de prueba e información que añadan valor agregado a la investigación subyace en el hecho en que cada solicitante puede tener pruebas adicionales que resulten útiles o necesarias para perseguir el cartel o, incluso, para entender su funcionamiento. Esta postura, consistente en permitir el acceso a los programas de clemencia a los siguientes solicitantes que sucedan a quien se acercó en primer lugar ante el organismo de competencia, se ha considerado por parte de la OCDE como una buena práctica que favorece el desarrollo de las investigaciones administrativas. ${ }^{26}$

A pesar de que tanto en el Decreto 2896 de 2010, como en el Decreto 1523 de 2015, los criterios de acceso a los programas de clemencia descartaban a los

23 Superintendencia de Industria y Comercio, Resolución 59363, Rad. 17-329492, 20 de septiembre de 2017 (Colombia).

24 De acuerdo con el artículo 2.2.2.29.2.2. del Decreto 1523 de 2015, el primer solicitante puede obtener la exoneración total de la multa por imponer. El segundo solicitante podrá obtener una reducción de la sanción entre el 30 y el $50 \%$, y al tercero y demás solicitantes posteriores se les otorgará una reducción de hasta el $20 \%$ de la multa por imponer (Colombia).

25 Decreto 1523/2015, op. cit.; Decreto 1074 de 2015, artículo 2.2.2.29.2.2. Orden y prelación para la obtención de beneficios por colaboración, op. cit. (Colombia).

26 Organization for Economic Co-operation and Development (OECD), Policy Roundtable: Leniency for subsequent applicants, DAF/COMP(2012)25, 2012, en http://www.oecd.org/competition/Leniencyforsubsequentapplicants2012.pdf 
promotores o instigadores de la conducta, el artículo 2.2.2.29.2.1. del Decreto 1523 de 2015 implementó una presunción a favor de todo aquel que solicite acceso al programa de clemencia. De esta forma, actualmente se presume que toda persona que solicite acceso al programa de clemencia no es el promotor o instigador de la conducta investigada. Por el contrario, le corresponderá a la persona que aduce que el solicitante es el instigador de la conducta, probar este hecho.

Otra de las novedades que implementó el Decreto 1523 de 2015, y que es un incentivo para adherirse a programas de beneficios por colaboración en Colombia, es la amnistía ampliada o amnesty plus que incluyó el artículo 2.2.2.29.4.1. De acuerdo con esta figura, el delator que, sin tener el primer puesto en el orden de prelación, sea el primer solicitante que informó de la existencia de acuerdos adicionales en otro mercado, antes de suscribir el programa de beneficios por colaboración dentro de la actuación en la que pretende recibir el beneficio, puede obtener una reducción de un $15 \%$ adicional de la multa por imponer.

Así, el sistema colombiano de protección de la libre competencia económica ha propendido por ampliar, a nivel administrativo sancionatorio, los beneficios a los que pueden acceder las personas incursas en acuerdos restrictivos de la competencia. La existencia de una posibilidad importante de reducción de la sanción es un incentivo decisivo al momento de solicitar acogerse a un programa de clemencia. No obstante lo anterior, la reducción de la sanción solamente resulta llamativa si se enfrenta con sanciones lo suficientemente altas que hagan más costosa la participación en la conducta anticompetitiva.

Con la expedición de la Ley 1340 de 2009, la legislación colombiana fortaleció las sanciones en favor de la libre competencia económica. ${ }^{27}$ En un estadio anterior, con el Decreto 2153 de 1992, se contemplaba que las sanciones a los infractores del régimen de la libre competencia económica solamente podían ascender a 2.000 salarios mínimos mensuales legales vigentes. Asimismo, para las personas naturales que hubiesen autorizado, ejecutado, colaborado, facilitado o tolerado las conductas violatorias del régimen de protección de la libre competencia económica las multas ascendían hasta 300 salarios mínimos legales mensuales vigentes.

Con la modificación introducida por los artículos 25 y 26 de la Ley 1340 de 2009 , los agentes del mercado que actualmente se encuentran inmersos en conductas restrictivas de la libre competencia económica pueden verse enfrentados a sanciones que ascienden hasta los 100.000 salarios mínimos mensuales vigentes $\mathrm{o}$, si resulta ser mayor el beneficio, hasta por el $150 \%$ de la utilidad

27 Congreso de la República. Proyecto de Ley 195 de 2007, en http://servoaspr.imprenta.gov.co/gacetap/gaceta. mos-trar_documento?p_tipo=05\&p_numero=195\&p_consec=17128exposición de motivos de la ley 1340 de 2009 
derivada de la conducta por parte del infractor. Por otra parte, las personas que colaboren, faciliten, autoricen, ejecuten o toleren conductas violatorias de las normas sobre protección de la competencia pueden verse expuestas a multas que ascienden a los 2.000 salarios mínimos legales mensuales vigentes.

Como se verá a continuación, el fortalecimiento de las sanciones por conductas restrictivas de la libre competencia económica en Colombia y en países de la región no se ha limitado al aumento del monto de las multas derivadas de las investigaciones administrativas, sino que, adicionalmente, estas prácticas se han tipificado como delito.

\section{El fortalecimiento de las sanciones por acuerdos restrictivos de la competencia y la exoneración total o parcial de la sanción por el acceso a los programas de beneficios por colaboración}

\subsection{Las conductas anticompetitivas criminalizadas en Estados Unidos, Chile, México y Brasil, y su tratamiento a través del acceso a los programas de beneficios por colaboración}

El fortalecimiento de las sanciones ha sido un cambio importante en la lucha contra los carteles empresariales. Una de las formas en las que algunos de los países han buscado fortalecer los sistemas de represión contra las conductas restrictivas de la libre competencia económica ha sido a través de su criminalización. ${ }^{28}$ Esto se fundamenta en que el riesgo de tener que asumir una responsabilidad penal y personal es un factor disuasorio de peso. ${ }^{29}$ De esta forma, la posibilidad para evitar una responsabilidad penal y personal por infracciones que atenten contra las normas que protegen la libre competencia económica pueden incentivar -de manera temprana- solicitudes de acceso a los programas de clemencia. ${ }^{30}$ Una razón lógica que explica esta situación ya ha sido evidenciada por la OCDE: "la responsabilidad penal por el comportamiento del cartel aumenta el costo de la conducta, proporcionando un efecto disuasorio adicional" ${ }^{31}$

Estados Unidos, Austria, Canadá, Irlanda, Israel, Japón, Corea y Noruega (ver Baker, The Use of Criminal Law Remedies to Deter and Punish Cartels and Bid-Rigging, op. cit., pp. 696, 705 y 710).

29 Organization for Economic Co-operation and Development (OECD) (2002), Fighting Hard-core Cartels: Harm, Effective Sanctions and Leniency Programmes, op. cit.

30 Idem.

31 Organization for Economic Co-operation and Development (OECD), Paper by the secretariat Felipe Serrano, op. cit. 


\section{Estados Unidos}

Un buen ejemplo de la aplicación de sanciones penales por acuerdos restrictivos de la libre competencia económica ha sido el implementado en Estados Unidos. Dentro de esta legislación, quienes vulneran el régimen de la libre competencia económica mediante actividades de cartel son tratados como criminales. ${ }^{32}$ Desde 1890, cuando el Congreso de Estados Unidos aprobó la Sherman Antitrust Act, hizo punibles las contravenciones de las secciones $1 \mathrm{y}$ 2 referentes a acuerdos anticompetitivos y el abuso de la posición de dominio. No obstante lo anterior, el Departamento de Justicia de Estados Unidos y las Cortes del mismo país crearon una distinción entre las conductas que deben ser sancionadas penalmente, de aquellas que deben serlo civil o monetariamente. Acuerdos como la fijación de precios, la colusión en contratación pública y la repartición de mercados y clientes, son sancionables penalmente. ${ }^{33}$

Una de las modificaciones importantes, introducidas en 1993 al programa de clemencia acogido por el Departamento de Justicia estadounidense, fue conceder inmunidad total de las sanciones penales a los directivos y empleados de las empresas ${ }^{34}$ que cooperaran con la autoridad de competencia..$^{35}$ Este esquema le ha permitido a Estados Unidos imponer, desde el año 2000, multas por ilícitos que vulneren la libre competencia económica que van desde 75 millones hasta 1,1 billones de dólares anuales. En efecto, el hecho de que el sistema penal norteamericano presente como institución fundamental la discrecionalidad de la acción penal materializada en el plea bragaining -o suplica negociada- le ha permitido lograr que "más del $90 \%$ de los imputados se declaren culpables a cambio de beneficios penales". ${ }^{36}$

A nivel latinoamericano, países como Chile, Brasil, México y Colombia también han penalizado los acuerdos anticompetitivos y sus regímenes han contemplado reducciones o exoneraciones de las sanciones por imponer a través de la suscripción de acuerdos de colaboración.

\section{Chile}

En el caso chileno fue a través de la Ley 20.945 del 30 de agosto de 2016 que se introdujeron modificaciones al Decreto Ley 211 de 1973, por el cual se fija-

Baker, The Use of Criminal Law Remedies to Deter and Punish Cartels and Bid-Rigging, op. cit., p. 693. Ibid., p. 697.

Estados Unidos, al igual que países como Austria, Canadá, Irlanda, Israel, Japón, Corea y Noruega consagran responsabilidad penal tanto a los individuos como a las empresas que se encuentren involucradas en acuerdos restrictivos de la competencia (ver Baker, The Use of Criminal Law Remedies to Deter and Punish Cartels and Bid-Rigging, op. cit., pp. 696, 705 y 710).

35 Sección A, Corporate Leniency Notice, Department of Justice, en https://www.justice.gov/atr/corporate-leniency-policy

36 Julio C. Montañez R., “Las negociaciones en el proceso penal: del procedimiento inquisitivo a la prisionización masiva", en Revista Derecho Penal y Criminología 34 (97) (2013), pp. 65-83. 
ron las normas para la defensa de la libre competencia. ${ }^{37}$ Por medio de estas modificaciones, se incorporó un sistema mixto de protección de la libre competencia económica que acude al derecho de la libre competencia como regla general, y al derecho penal como medio de reacción frente a los carteles duros. ${ }^{38}$ Es así como, además de considerarse como prácticas anticompetitivas, los acuerdos de fijación de precios, la limitación de producción, la repartición de mercado y la afectación del resultado de licitaciones públicas, ${ }^{39}$ también $^{2}$ son considerados como un delito. ${ }^{40}$

En el sistema chileno, el fortalecimiento de las sanciones por prácticas anticompetitivas a través de la tipificación penal de los acuerdos anticompetitivos buscó, en primer lugar, proteger derechos sociales o colectivos mediante un mecanismo de tutela que opera desde la mera puesta en peligro del bien jurídico tutelado, para generar una mayor prevención general. En segundo lugar, este fortalecimiento también buscó incentivar las solicitudes de acceso a los programas de beneficios por colaboración. A nivel administrativo, como a nivel penal, quienes accedan al programa de clemencia pueden llegar a obtener la exoneración total de la sanción por imponer.

En efecto, de acuerdo con el artículo 39 bis del Decreto Ley 211 de 1973, ${ }^{41}$ quienes aporten información que le permita a la Fiscalía Nacional Económica

37 Decreto Ley 211 de 1973 del Ministerio de Economía, Fomento y Reconstitución, por medio del cual se fijan "normas para la defensa de la libre competencia". Texto refundido, coordinado y sistematizado mediante el Decreto con fuerza de Ley 1 de 2004 del Ministerio de Economía, Fomento y Reconstitución. Últimas modificaciones introducidas por medio del Proyecto de Ley inscrito el 8 de julio de 2016 modificando el Decreto Ley 1 de 2004 que refundió el Decreto Ley 211 de 1973 y la Ley 20.945 del 30 de agosto de 2016, por medio de la cual se "perfecciona el sistema de defensa de la libre competencia" (Chile), en https://www.fne.gob.cl/ wp-content/uploads/2010/12/DL_211_refundido_2016.pdf

38 Osvaldo Artaza V., Matías Belmonte P., Germán Acevedo M., “El delito de colusión en Chile: propuesta analítica de la conducta prohibida a través de su interpretación como un acuerdo anticompetitivo", Revista Ius et Praxis 24 (2) (2018), pp. 549-592, en https://scielo.conicyt.cl/pdf/iusetp/v24n2/0718-0012-iusetp-24-02-00549.pdf

39 Decreto Ley 211/1973, art. 3. “El que ejecute o celebre, individual o colectivamente cualquier hecho, acto o convención que impida, restrinja o entorpezca la libre competencia, o que tienda a producir dichos efectos, será sancionado con las medidas señaladas en el artículo 26 de la presente ley, sin perjuicio de las medidas preventivas, correctivas o prohibitivas que respecto de dichos hechos, actos o convenciones puedan disponerse en cada caso. Se considerarán, entre otros, como hechos, actos o convenciones que impiden, restringen o entorpecen la libre competencia o que tienden a producir dichos efectos, los siguientes: a) Los acuerdos o prácticas concertadas que involucren a competidores entre sí, y que consistan en fijar precios de venta o de compra, limitar la producción, asignarse zonas o cuotas de mercado o afectar el resultado de procesos de licitación, así como los acuerdos o prácticas concertadas que, confiriéndoles poder de mercado a los competidores, consistan en determinar condiciones de comercialización o excluir a actuales o potenciales competidores" (Chile).

40 Decreto Ley 211/1973, artículo 62. "El que celebre u ordene celebrar, ejecute u organice un acuerdo que involucre a dos o más competidores entre sí, para fijar precios de venta o de compra de bienes o servicios en uno o más mercados; limitar su producción o provisión; dividir, asignar o repartir zonas o cuotas de mercado; o afectar el resultado de licitaciones realizadas por empresas públicas, privadas prestadoras de servicios públicos, u órganos públicos, será castigado con la pena de presidio menor en su grado máximo a presidio mayor en su grado mínimo" (Chile).

41 Decreto Ley 211/1973, artículo 39 Bis. "El que intervenga en alguna de las conductas previstas en la letra a) del artículo $3^{\circ}$ podrá ser eximido de la disolución contemplada en la letra b) del artículo 26 y obtener una exención o reducción de la multa a que se refiere la letra c) de dicho artículo, en su caso, cuando aporte a la Fiscalía Nacional Económica antecedentes que conduzcan a la acreditación de dicha conducta y a la determinación de los responsables" (Chile). 
acreditar i) la conducta investigada y ii) los responsables involucrados, pueden obtener una exención total de la multa. En caso de ser los segundos solicitantes, pueden obtener una reducción en la sanción que no puede superar el $50 \%$ de la multa. Por otra parte, de acuerdo con el artículo 63 de este cuerpo normativo, también pueden exonerarse de responsabilidad penal quienes se acerquen a colaborar en primer lugar con la Fiscalía Nacional Económica. ${ }^{42}$ Así, a pesar de que en los procesos administrativos se permite el acceso a los programas de beneficios por colaboración tanto del primer como del segundo solicitante, mientras que en lo que respecta a la sanción penal solamente se admite al primer solicitante, resulta cierto que el fortalecimiento de las sanciones tiende a estar ligado al aumento de incentivos para delatar. Lo que propende por la efectividad de este mecanismo.

\section{México}

De igual manera, el modelo mexicano incorporó un sistema mixto para la protección de la libre competencia económica. Dentro de este régimen se reprimen las prácticas anticompetitivas en la órbita administrativa, a cargo de la Comisión Federal de Competencia Económica, y a nivel penal, a cargo de la Fiscalía General de la República. De acuerdo con el artículo 53 de la Ley Federal de Competencia Económica, ${ }^{43}$ se han considerado como prácticas monopólicas absolutas: los acuerdos de fijación de precios, la limitación de producción de bienes y servicios, la repartición de mercados, la coordinación de posturas o su abstención en procesos de contratación pública y el intercambio de información que tenga como objeto o efecto las anteriores infracciones.

42 Decreto Ley 211/1973, artículo 63. “Estarán exentos de responsabilidad penal por el delito tipificado en el artículo 62 aquellas personas que primero hayan aportado a la Fiscalía Nacional Económica antecedentes de -conformidad al artículo 39 bis. El requerimiento del Fiscal Nacional Económico individualizará a las personas exentas de responsabilidad penal y dicha calidad será así declarada por el Tribunal de Defensa de la Libre Competencia. Las personas indicadas en el inciso anterior deberán proporcionar al Ministerio Público y al tribunal competente los mismos antecedentes que previamente entregaron a la Fiscalía Nacional Económica, y deberán prestar declaración en calidad de testigo en la forma dispuesta por el artículo 191 del Código Procesal Penal, declaración que será incorporada al juicio oral de la manera prevista en el artículo 331 del mencionado Código" (Chile).

43 Ley Federal de Competencia, artículo 53. “Se consideran ilícitas las prácticas monopólicas absolutas, consistentes en los contratos, convenios, arreglos o combinaciones entre Agentes Económicos competidores entre sí, cuyo objeto o efecto sea cualquiera de las siguientes: I. Fijar, elevar, concertar o manipular el precio de venta o compra de bienes o servicios al que son ofrecidos o demandados en los mercados; II. Establecer la obligación de no producir, procesar, distribuir, comercializar o adquirir sino solamente una cantidad restringida o limitada de bienes o la prestación o transacción de un número, volumen o frecuencia restringidos o limitados de servicios; III. Dividir, distribuir, asignar o imponer porciones o segmentos de un mercado actual o potencial de bienes y servicios, mediante clientela, proveedores, tiempos o espacios determinados o determinables; IV. Establecer, concertar o coordinar posturas o la abstención en las licitaciones, concursos, subastas o almonedas, y V. Intercambiar información con alguno de los objetos o efectos a que se refieren las anteriores fracciones. Las prácticas monopólicas absolutas serán nulas de pleno derecho, y en consecuencia, no producirán efecto jurídico alguno y los Agentes Económicos que incurran en ellas se harán acreedores a las sanciones establecidas en esta Ley, sin perjuicio de la responsabilidad civil y penal que, en su caso, pudiere resultar" (México). 
El artículo 254 Bis del Código Penal Federal estableció que las prácticas monopólicas absolutas son consideradas también como delito. ${ }^{44}$ Estas pueden ser sancionadas con penas privativas de la libertad que pueden oscilar entre 5 a 10 años de prisión.

Dentro del régimen mexicano, cualquier agente económico que se encuentre inmerso en una práctica anticompetitiva puede reconocer su conducta y acogerse al beneficio de reducción de la sanción, establecida en el artículo 103 de la Ley Federal de Competencia Económica. ${ }^{45}$ Conforme a esta norma, el primer delator que aporte los elementos de convicción suficientes puede acceder, en sede administrativa, a la imposición de una multa mínima. Así mismo, quienes no lleguen en primer lugar de marcaje pueden verse beneficiados de una reducción del 50, 30 o $20 \%$ del máximo permitido. Ahora bien, en sede penal, el beneficio consiste en no dictar sentencia en contra de aquellos agentes económicos que se acojan a los programas de beneficios por colaboración.

De igual manera, en el mexicano el aumento de las sanciones se encuentra ajustado a los incentivos para solicitar acceso al programa de clemencia. Los infractores de las normas que protegen la libre competencia económica pueden sopesar, si continúan en la conducta anticompetitiva o sí, por el contrario, solicitan acceso al programa de beneficios por colaboración con la posibilidad de obtener una multa mínima en sede administrativa y exonerarse de recibir sentencia en contra en sede penal.

44 Código Penal Federal, artículo 254 Bis. “Se sancionará con prisión de cinco a diez años y con mil a diez mil días de multa, a quien celebre, ordene o ejecute contratos, convenios, arreglos o combinaciones entre agentes económicos competidores entre sí, cuyo objeto o efecto sea cualquiera de los siguientes: I. Fijar, elevar, concertar o manipular el precio de venta o compra de bienes o servicios al que son ofrecidos o demandados en los mercados; II. Establecer la obligación de no producir, procesar, distribuir, comercializar o adquirir sino solamente una cantidad restringida o limitada de bienes o la prestación o transacción de un número, volumen o frecuencia restringidos o limitados de servicios; III. Dividir, distribuir, asignar o imponer porciones o segmentos de un mercado actual o potencial de bienes y servicios, mediante clientela, proveedores, tiempos o espacios determinados o determinables; IV. Establecer, concertar o coordinar posturas o la abstención en las licitaciones, concursos, subastas o almonedas, y V. Intercambiar información con alguno de los objetos o efectos a que se refieren las anteriores fracciones. [...] No existirá responsabilidad penal para los agentes económicos que se acojan al beneficio a que se refiere el artículo 103 de la Ley Federal de Competencia Económica, previa resolución de la Comisión Federal de Competencia Económica o del Instituto Federal de Telecomunicaciones que determine que cumple con los términos establecidos en dicha disposición y las demás aplicables" (México).

45 Ley Federal de Competencia, artículo 103. “Cualquier Agente Económico que haya incurrido o esté incurriendo en una práctica monopólica absoluta; haya participado directamente en prácticas monopólicas absolutas en representación o por cuenta y orden de personas morales; y el Agente Económico o individuo que haya coadyuvado, propiciado, inducido o participado en la comisión de prácticas monopólicas absolutas, podrá reconocerla ante la Comisión y acogerse al beneficio de la reducción de las sanciones establecidas en esta Ley, siempre y cuando: I. Sea el primero, entre los Agentes Económicos o individuos involucrados en la conducta, en aportar elementos de convicción suficientes que obren en su poder y de los que pueda disponer y que a juicio de la Comisión permitan iniciar el procedimiento de investigación o, en su caso, presumir la existencia de la práctica monopólica absoluta; II. Coopere en forma plena y continua en la sustanciación de la investigación y, en su caso, en el procedimiento seguido en forma de juicio III. Realice las acciones necesarias para terminar su participación en la práctica violatoria de la Ley" (México). 


\section{Brasil}

El sistema legislativo brasilero modificó, en el año 2011, la estructura del sistema de defensa de la libre competencia económica por medio de la Ley 12.529. De acuerdo con esta Ley, se consideran como infracciones del orden económico, entre otras: i) la fijación de precios o servicios, ii) la limitación de producción o de bienes o servicios, iii) la repartición de mercado o distribución de clientes, iv) el abuso de la posición de dominio y v) acordar, ajustar o manipular los precios, condiciones, ventajas o abstención en licitaciones públicas. ${ }^{46}$ Quienes se encuentran incursos en las conductas que restrinjan la libre competencia económica, son sancionados con multas que oscilan entre 0,1 al $20 \%$ del monto de las ventas de la empresa en el último año anterior al inicio del trámite administrativo. Para las personas naturales o jurídicas de derecho privado o público, que no ejerzan actividad empresarial, las multas por imponer se encuentran entre $\$ 50.000$ y $\$ 2.000 .000 .000$ reales.

Por su parte, en el artículo 4 de la Ley 8.137 de 1990, modificado por el artículo 116 de la Ley 12.529 de 2011, se establece que las personas que se encuentran incursas en i) un abuso de posición de dominio o ii) pacten, convengan, acuerden o ajusten entre oferentes la fijación artificial de precios o cantidades vendidas, ejerzan un control regionalizado del mercado por empresa o grupo de empresas y controlen la red de distribución o de proveedores en detrimento de la libre competencia económica, podrán verse expuestos a penas privativas de la libertad que oscilan entre los 2 y 5 años. ${ }^{47}$

Uno de los cambios introducidos por el artículo 87 de la Ley 12.529 de 2011 consistió en incluir que los infractores que decidieran acogerse al programa de beneficios por colaboración no serían procesados penalmente por ningún delito cometido en contra de la ley antimonopolio. Decretar la extinción de la acción punitiva en favor del infractor -incluido el instigador- está dado solamente para aquellos casos en los que la solicitud de acceso al programa de beneficios por colaboración haya sido presentada ante la Superintendencia General sin que esta haya tenido conocimiento previo de la infracción denunciada. ${ }^{48}$

46 Son perseguidas por el Sistema Brasilero de Defensa de la Competencia, integrado por el Consejo Administrativo de Defensa Económica y por la Secretaría de Monitoreo Económico del Ministerio de Hacienda.

47 Ley 8.137 de 1990, artículo 4. Modificado por el artículo 106 de la Ley 12.529 de 2011. "Es un delito contra el orden económico: I - abusar del poder económico, dominar el mercado o eliminar, total o parcialmente, la competencia mediante cualquier forma de ajuste o acuerdo de las empresas; II - formar un acuerdo, acuerdo, ajuste o alianza entre oferentes, con el objetivo de: a) fijación artificial de precios o cantidades vendidas o producidas; b) control regionalizado del mercado por compañía o grupo de compañías; c) control, en detrimento de la competencia, de la red de distribución o proveedores. Pena - prisión, de 2 (dos) a 5 (cinco) años y una multa". (Traducción libre) (Brasil).

48 Ley 12.529/2011, artículo 87. “En delitos contra el orden económico, tipificados en la Ley 8.137, de 27 de diciembre de 1990 , y en otros delitos directamente relacionados con la práctica del cartel, como los tipificados en la Ley 8.666, de 21 de junio de 1993 y los tipificados en el art. 288 del Decreto Ley ${ }^{\circ} 2.848$, de 7 de diciembre de 1940 - El Código Penal, la firma de un acuerdo de clemencia, bajo los términos de esta Ley, determina la suspensión del plazo del estatuto de limitaciones y evita la oferta de la queja en relación con el agente beneficiario del lenidad. Párrafo único. Una vez que el agente ha cumplido el acuerdo de clemencia, el castigo por los delitos mencionados en el artículo de este artículo se extingue automáticamente" (Traducción libre) (Brasil). 
En una situación distinta, después de iniciada la investigación, se concederá solamente una reducción entre uno a dos tercios de la sanción aplicable que dependerá del cumplimiento de los criterios de graduación de la sanción, tales como: la colaboración dada y la buena fe del infractor en el cumplimiento del acuerdo de clemencia. Los segundos y siguientes delatores que se acojan al programa de clemencia solo se verán beneficiados de una reducción de la sanción si reconocen su participación en un segundo cartel -Amnistía Ampliada o Amnesty Plus-y proporcionan pruebas que le permitan a la autoridad de competencia descubrir el cartel empresarial.

Hasta este punto resulta relevante mencionar que, a efectos de propender por la efectividad de los programas de delación o clemencia, la experiencia regional permite entrever un uso generalizado de la exoneración de la sanción administrativa y penal, para aquellos infractores que se encuentran inmersos en prácticas restrictivas de la competencia y que decidan acogerse, en primer lugar, a los programas de clemencia. No debe perderse de vista que en la medida en que las prácticas restrictivas de la competencia sean sancionables administrativa y penalmente se incrementa el costo de participación en la conducta anticompetitiva. De allí que los países estudiados acompasen el aumento de las sanciones, con un incremento en los beneficios para acogerse a los programas de beneficios por colaboración.

Con el propósito de integrar algunas de las características estudiadas de los regímenes abordados, en la tabla 1 se resumen algunas de las características relevantes que interesan en el presente artículo.

Tabla 1. Prácticas restrictivas penalizables en los países estudiados y beneficios derivados de los programas de clemencia

\begin{tabular}{|c|c|c|c|}
\hline Estados Unidos & Chile & México & Brasil \\
\hline $\begin{array}{l}\text { Sherman Antitrust } \\
\text { Act de } 1980\end{array}$ & Ley 211 de 1973 & $\begin{array}{l}\text { Ley Federal de } \\
\text { Competencia de } 2017\end{array}$ & Ley 12.529 de 2011 \\
\hline $\begin{array}{l}\text { - Abuso de posición } \\
\text { de dominio. } \\
\text { - Fijación de precios. } \\
\text { - Repartición } \\
\text { de mercados y } \\
\text { clientes. } \\
\text { - Colusión en } \\
\text { contratación } \\
\text { pública. }\end{array}$ & $\begin{array}{l}\text { - Limitación en la } \\
\text { producción de } \\
\text { bienes y servicios. } \\
\text { - Fijación de } \\
\text { precios. } \\
\text { - Repartición de } \\
\text { mercados. } \\
\text { - Colusión en } \\
\text { contratación } \\
\text { pública. }\end{array}$ & $\begin{array}{l}\text { - Limitación en la } \\
\text { producción de } \\
\text { bienes y servicios. } \\
\text { - Fijación de precios. } \\
\text { - Repartición de } \\
\text { mercados. } \\
\text { - Colusión en } \\
\text { contratación } \\
\text { pública. }\end{array}$ & $\begin{array}{l}\text { - Abuso de posición } \\
\text { de dominio. } \\
\text { - Acuerdo entre } \\
\text { oferentes que fijen } \\
\text { artificialmente } \\
\text { precios o } \\
\text { cantidades; } \\
\text { controlen por } \\
\text { regiones el } \\
\text { mercado; y control } \\
\text { de la red de } \\
\text { distribución. }\end{array}$ \\
\hline $\begin{array}{l}\text { Inmunidad total } \\
\text { de las sanciones } \\
\text { penales. }\end{array}$ & $\begin{array}{l}\text { Exoneración de } \\
\text { responsabilidad } \\
\text { penal para el } \\
\text { primer solicitante. }\end{array}$ & $\begin{array}{l}\text { Exoneración de la } \\
\text { sanción al no dictar } \\
\text { sentencia en contra. }\end{array}$ & $\begin{array}{l}\text { Extinción de la } \\
\text { acción punitiva en } \\
\text { favor del infractor. }\end{array}$ \\
\hline
\end{tabular}




\subsection{La criminalización de la colusión en contratación pública en Colombia}

En la legislación colombiana, a la fecha, únicamente se ha tipificado la colusión en contratación pública como delito. Su tipificación se concibió como un instrumento orientado a fortalecer los mecanismos de prevención, investigación y sanción en contra de los actos de corrupción en procura de la efectividad y el control de la gestión pública.

La corrupción ha sido definida por la literatura especializada como:

La desviación del interés público, que se desarrolla a través del abuso del cargo, con el fin de obtener un beneficio extraposicional en la administración pública o en la empresa privada. Este concepto es plenamente aplicable a la corrupción pública como también a la corrupción privada, pues ambas tienen como elemento común la desviación de intereses para la obtención de beneficios extraposicionales en la administración de intereses ajenos. ${ }^{49}$

La colusión en contratación pública no necesariamente implica la participación de un servidor público para su comisión, pues se trata de un acuerdo anticompetitivo que, independientemente de la forma en que se constituya, es celebrado entre personas que tienen el deber de competir en caso de que concurran en un proceso de contratación pública. Una de las razones por las cuales se tipificó la colusión como delito radica en el hecho de que los carteles empresariales, en el marco de procesos de contratación pública, eliminan la rivalidad entre los ofertes que están llamados a competir, encarecen los bienes o servicios requeridos por las entidades estatales y afectan los recursos públicos o sociales del Estado. ${ }^{50}$

Este tipo de conductas han sido consideradas como unas de las infracciones a la libre competencia de mayor impacto, debido a que no solo vulneran el derecho colectivo constitucional de la libre competencia económica, sino que también afectan los bienes y recursos públicos. ${ }^{51}$ Así, resulta reprochable que proponentes que participen en un mismo proceso de contratación pública, realicen cualquier tipo de práctica o conducta coordinada que tenga la potencialidad de modificar artificialmente los resultados de la adjudicación de un contrato con el gobierno, defraudando el interés público en el cumplimiento de los fines estatales.

49 Carlos Guillermo Castro Cuenca, La corrupción pública y privada: causas, efectos y mecanismos para combatirla, Bogotá, Ed. Universidad del Rosario, 2017, pp. 23 y 36.

50 Andrés Palacios Lleras, "La lucha contra los carteles empresariales en la contratación estatal en Colombia", Latin American Law Review 03 (2019), pp. 117-134. Doi: https://doi.org/10.29263/lar03.2019.06

51 Superintendencia de Industria y Comercio, Caso "INVÍAS", Rad. 17-401804. Resolución de Sanción 73323 del 18 de noviembre de 2020. 
En el año 2011, el Congreso de Colombia promulgó la Ley 1474 de 2011 o Estatuto Anticorrupción, mediante el cual introdujo el artículo 410A en el Código Penal Colombiano. A través de este artículo se tipificaron como delito los acuerdos restrictivos de la competencia que se surtan en el marco de procesos de contratación estatal. El tipo penal introducido señala que quien "en un proceso de licitación pública, subasta pública, selección abreviada o concurso se concertare con otro con el fin de alterar ilícitamente el procedimiento contractual" puede verse expuesto a: i) una pena privativa de la libertad que oscila entre 6 a 12 años; ii) una multa entre 200 a 1.000 salarios mínimos legales mensuales vigentes; $y$, iii) una inhabilidad para contratar con entidades estatales por 8 años.

La Ley 1474 de 2011 creó una distinción entre las conductas que merecen ser sancionadas penalmente, de aquellas que se satisfacen con sanciones exclusivamente monetarias. Tal como se indicó en el capítulo anterior, la inclusión de prácticas restrictivas de la libre competencia económica como tipo penal constituye un ejemplo de cómo se busca fortalecer las sanciones y reprimir -con mayor severidad- este tipo de conductas.

En el caso colombiano, a diferencia de los demás países de la región en los cuales se han criminalizado conductas anticompetitivas, solamente se tipificó la colusión en contratación pública como un delito. Esto se debe a que la lucha por la que propendió el legislador colombiano fue en contra de la corrupción, resguardando como bien jurídico tutelado la administración pública, mas no el derecho de la libre competencia económica. Su significado político criminal no se encontraba en la realización instrumental de aplicación del texto de la ley de competencia, sino que su lucha se encontraba dirigida a atacar la corrupción del país.

Este fenómeno ha sido reconocido por la literatura como derecho simbólico. En este, la prohibición estatal no solo tiene como una de sus funciones evitar o minimizar el comportamiento prohibido, sino que "tras este existen valores culturales y morales que simbolizan un determinado estilo de vida, y que son colonizados por medio de la prohibición penal" ${ }^{52}$ De allí que pueda entenderse que Colombia sea el único de los países aquí estudiados en el cual no se implementó una inmunidad penal como beneficio para incentivar solicitudes de acceso a los programas de beneficios por colaboración ofrecidos por la Superintendencia de Industria y Comercio. En efecto, de acuerdo con el parágrafo del citado artículo 410A del Código Penal colombiano, quien:

52 Winfried Hassemer, "Derecho penal simbólico y protección de bienes jurídicos", en Varios Autores, Pena y Estado, Editorial Jurídica Conosur, 1995, pp. 23-36, en https://perso.unifr.ch/derechopenal/assets/files/obrasportales/op_20130708_01.pdf 
... en su condición de delator o clemente mediante resolución en firme obtenga exoneración total de la multa a imponer por parte de la Superintendencia de Industria y Comercio en una investigación por acuerdo anticompetitivos en un proceso de contratación pública obtendrá los siguientes beneficios: reducción de la pena en una tercera parte, un $40 \%$ de la multa a imponer y una inhabilidad para contratar con entidades estatales por cinco (5) años.

A pesar de que la política criminal tenía la intención de desincentivar la comisión de la conducta, tuvo un efecto adverso. De acuerdo con el análisis que se realizará a continuación, la criminalización de la colusión en procesos de contratación pública podría evidenciar una falta de incentivos suficientes para acogerse a los programas de clemencia. La razón radica en que la tipificación de la colusión en contratación pública como delito solamente contempló la opción de una reducción de un tercio de la pena intramural en aquellos casos en los que el cartelista o infractor, haya sido exonerado totalmente de la multa a imponer por la suscripción de un convenio de beneficios por colaboración con la autoridad de competencia. De esta manera, el incentivo para delatar resulta ser superado por el riesgo de ser enviado a prisión. Esta desconexión entre la política criminal y los programas de beneficios por colaboración habría desincentivado la participación de personas en los programas de clemencia ofrecidos por la Superintendencia de Industria y Comercio. ${ }^{53}$ No debe perderse de vista que, por un lado, las normas no solo deben ser correctas, sino que deben ser también eficaces y, por otro lado, "las decisiones penales representan solo un minúsculo tornillo (del cual no siempre se sabe en qué dirección gira)" ${ }^{54}$

\section{La experiencia colombiana: comparación entre la implementación del programa de clemencia en las investigaciones por colusión versus las demás prácticas restrictivas de la competencia}

Como se verá a continuación, eximir de responsabilidad penal y administrativa a aquellas personas incursas en conductas restrictivas de la libre competencia económica, que se acojan en primer lugar de marcaje a los programas de beneficios por colaboración ofrecidos por la Superintendencia de Industria y

53 De acuerdo con la Corte Suprema de Justicia de los Estados Unidos, “las negociaciones son necesarias y hasta deseables, [...] pues entiende que ningún sistema penal contemporáneo podría hacer frente a la inmensa criminalidad en el mundo sin acudir a mecanismos utilitarios que contribuyan en su labor; esta postura es defendida por el reconocido procesalista E. L. Chiesa Aponte, quien afirma que 'hoy día se le acepta como un componente esencial de nuestro sistema de justicia criminal' y que, en el peor de los casos, las negociaciones deben ser entendidas como 'una especie de mal necesario'"' (Julio C. Montañez R., Las negociaciones en el proceso penal: del procedimiento inquisitivo a la prisionización masiva, en Revista Derecho Penal y Criminología 34 (97) (2013), pp. 65-83.

54 Hassemer, “Derecho penal simbólico y protección de bienes jurídicos”, op. cit., pp. 23-36. 
Comercio, podría generar un incentivo adicional para solicitar acceso a estos programas de clemencia. Con ello, se podrían materializar los fines por los que propende este mecanismo, al hacer más costosa la conducta anticompetitiva ${ }^{55}$ a través del fortalecimiento de las sanciones por imponer, pero con incentivos reales de ser exonerados de las sanciones penales y administrativas que de otra forma les serían impuestas.

Hasta este punto se han identificado elementos que son importantes al momento de evaluar la efectividad de los programas de beneficios por colaboración. El primero de ellos, es que existan beneficios por colaboración realmente atractivos para el delator. El segundo, es que existan multas suficientemente altas que hagan más costosa la conducta para los infractores; $y$, el tercero, que exista una percepción por parte del cartel de que pueden ser detectados por la autoridad competente. Tal como lo ha sostenido la OECD:

Los miembros del cártel deben sentir que existe un alto riesgo de detección para que tengan incentivos para presentar una solicitud de clemencia ante el organismo de competencia. Si los agentes del mercado perciben que la autoridad de defensa de la competencia no tiene suficientes facultades de investigación (tanto desde el punto de vista legal como práctico), no tendrán incentivos para solicitar la clemencia, incluso cuando los cárteles se sancionan con importantes multas. ${ }^{56}$

En Colombia, el porcentaje de los casos que han sido finalmente sancionados en los últimos 10 años, con relación al número de aperturas de investigación que a la fecha ${ }^{57}$ han sido decididas por acuerdos restrictivos de la libre competencia económica en la Superintendencia de Industria y Comercio, asciende al $79,36 \%{ }^{58}$ Esto significa que existe una alta probabilidad de que los casos que son investigados por la Superintendencia de Industria y Comercio sean finalmente sancionados. Si a ese factor se adiciona el hecho de que esa autoridad de competencia cuenta con unas de las facultades más amplias de investigación a nivel latinoamericano, se crea una percepción de que existe una probabilidad razonable de que los cartelistas sean sancionados. En otras palabras, esto se traduce en un aliciente para solicitar acceso a los programas de clemencia.

55 "El punto de partida de la teoría de la elección racional es que los delincuentes buscan obtener beneficios de su conducta criminal, y esta situación envuelve la adopción de decisiones y de elecciones racionales. Sin embargo, la decisión de cometer un crimen específico no solamente depende de las necesidades del sujeto, sino del contexto situacional y de la información disponible sobre este. En resumen, el individuo tiene en cuenta las utilidades esperadas producto de su comportamiento criminal y no criminal y, si cometer un crimen tiene mayor utilidad que no cometerlo -implica que existe un riesgo aceptable de ser capturado menor que la cantidad considerable a ganar-" (Castro Cuenca, La corrupción pública y privada, op. cit., p. 26).

56 Organization for Economic Co-operation and Development (OECD), Paper by the secretariat Felipe Serrano, op. cit.

57 Información corroborada hasta el 27 de junio de 2020

58 Este porcentaje corresponde con el total de sanciones impuestas por investigaciones iniciadas en el Grupo Élite contra Colusiones y en los Grupos de Trabajo de Prácticas Restrictivas de la Competencia y de Protección y Promoción de la Competencia, por acuerdos restrictivos de la competencia y por infracciones de la prohibición general, contenida en el artículo 1 de la Ley 155 de 1959 estatal, desde 2009 a junio de 2020, que corresponde a 50 , sobre el total de las investigaciones abiertas y decididas por estas conductas durante el periodo de tiempo mencionado que corresponden a 63. 
Sin embargo, debe llamarse la atención sobre un aspecto importante. A pesar de i) la efectividad en las investigaciones y la probable percepción sobre el alto riesgo de detección en procesos investigados por la Superintendencia de Industria y Comercio y, ii) además, dado el fortalecimiento de las sanciones adoptadas a nivel administrativo -introducidas por los artículos 25 y 26 de la Ley 1340 de 2009-, lo cierto es que solicitar acceso a los programas de clemencia en Colombia no ha sido la regla general.

A pesar de que, desde la expedición de la Ley 1340 de 2009 existe la posibilidad de solicitar acceso a los programas de clemencia, no fue sino hasta el año 2014 que se presentó la primera solicitud de acceso al programa de beneficios por colaboración ofrecido por la Superintendencia de Industria y Comercio. Desde ese entonces, hasta la actualidad, el número de casos en los cuales se ha solicitado acceso al programa de clemencia asciende a un total de 10 investigaciones.

Ahora bien, para analizar la efectividad de estos programas de clemencia en Colombia se tendrán en cuenta todas las resoluciones de apertura de investigación dentro de las que resulta posible solicitar acceso a los programas de beneficios por colaboración. Es decir, todos aquellos casos en los que existe i) un acuerdo restrictivo de la competencia -como sucedió, por ejemplo, en el caso de PAE Frutas (Rad. 17-292981 ${ }^{59}$ )-; ii) una infracción de la prohibición general contenida en el artículo 1 de la Ley 155 de $1959^{60}$-como ocurrió en los casos de Boletería (Rad. 17-32721561) y Vigilancia (Rad. 11-7159062)-; o, iii) una imputación en la que concurran ambas conductas -como ocurrió en los casos de Cloro Soda (Rad. 17-288979) ${ }^{63}$, Tubería (Rad. 16-453444) ${ }^{64}$, Mineros (Rad. 14-130744) ${ }^{65}$, Cuadernos (Rad.

59 Superintendencia de Industria y Comercio, Caso "PAE Frutas", Rad. 17-292981. Resolución de apertura de investigación 2065 de 2015, en http://normograma.info/sic/docs/pdf/r_siyc_2065_2015.pdf. Resolución de imposición de sanción 71584 de 2019, en http://normograma.info/sic/docs/r_siyc_71584_2019.htm

$60 \mathrm{Al}$ respecto deben hacerse dos precisiones. La primera es que el artículo 1 de la Ley 155 de 1959 fue declarado exequible por la Corte Constitucional en Sentencia C-032 del 25 de enero de 2017. La segunda, es que para que exista la posibilidad de acceder a los programas de clemencia, en la conducta investigada que infrinja el artículo 1 de la Ley 155 de 1959 debe haber al menos dos agentes de mercado.

61 Superintendencia de Industria y Comercio, Caso “Boletería”, Rad. 17-327215. Resolución de apertura de investigación 53719 de 2018, en http://normograma.info/sic/docs/r_siyc_53719_2018.htm. Caso pendiente de decisión.

62 Superintendencia de Industria y Comercio, Caso “Vigilancia”, Rad. 17-327215. Resolución de apertura de investigación 2065 de 2015, en http://normograma.info/sic/docs/r_siyc_53719_2018.htm. Resolución de imposición de sanción 19890 de 2017, en http://normograma.info/sic/docs/r_siyc_19890_2017.htm

63 Superintendencia de Industria y Comercio, Caso "Cloro Soda", Rad. 17-288979. Resolución de apertura de investigación 6059 de 2019, en http://normograma.info/sic/docs/pdf/resolucion_superindustria_6059_2019.pdf. Resolución de imposición de sanción 57600 de 2019, en http://normograma.info/sic/ docs/r_siyc_57600_2019.htm

64 Superintendencia de Industria y Comercio, Caso “Tubería”, Rad. 16-453444. Resolución de apertura de investigación 24831 de 2017, en http://normograma.info/sic/docs/r_siyc_24831_2017.htm. Resolución de imposición de sanción 39386 de 2019, en http://normograma.info/sic/docs/r_siyc_39386_2019.htm

65 Superintendencia de Industria y Comercio, Caso "Mineros", Rad. 14-130744. Resolución de apertura de investigación 53015 de 2016, en http://normograma.info/sic/docs/r_siyc_53015_2016.htm. Caso pendiente de decisión. 
14-151036) ${ }^{66}$, Pañales (Rad.13-266923) $)^{67}$, Papeles Suaves (Rad.14-151027) ${ }^{68} \mathrm{y}$ Ruta del Sol (Rad.17-14777) ${ }^{69}-$.

Una razón importante subyace a este hecho: los programas de beneficios por colaboración son aplicables a aquellas conductas en las que existan al menos dos agentes económicos que se concierten para restringir la libre competencia económica. Por esta razón, podría afirmarse que dentro de cada proceso de investigación hay al menos un investigado que tiene la posibilidad de solicitar acceso a los programas de beneficios por colaboración. Lo anterior debido a que, si bien esta figura tiene aplicación en conductas en las que existen acuerdos restrictivos de la competencia o en las que se infringe la norma de prohibición general contenida en el artículo 1 de la Ley 155 de 1992, ${ }^{70}$ habrá al menos un investigado que tenga la posibilidad de delatar, pues su cómplice sería el instigador de la conducta que no tiene la posibilidad, probada su condición, de acceder a los programas de beneficios por colaboración.

Desde el año 2009, en Colombia se ha dado apertura a 79 investigaciones por acuerdos restrictivos de la libre competencia económica y por infracciones de la prohibición general, contenida en el artículo 1 de la Ley 155 de 1959 estatal. ${ }^{71}$ Sin embargo, solamente en 10 de ellas se ha solicitado acceso al programa de clemencia. Si se diferenciaran aquellos casos ocurridos en el sector público con ocasión de un proceso de contratación estatal- de aquellos que ocurren en el mercado en general o privado, se obtiene que: i) en las investigaciones del actual Grupo Élite contra Colusiones ${ }^{72}$ solamente en un 7,6 \% ${ }^{73}$ de los casos investigados se solicita acceso al programa de beneficios por colaboración, mientras que, (ii) en las investigaciones realizadas por los Grupos de Trabajo

66 Superintendencia de Industria y Comercio, Caso “Cuadernos”, Rad. 14-151036. Resolución de apertura de investigación 7897 de 2015, en http://normograma.info/sic/docs/r_siyc_7897_2015.htm. Resolución de imposición de sanción 54403 de 2016, en http://normograma.info/sic/docs/r_siyc_54403_2016.htm

67 Superintendencia de Industria y Comercio, Caso "Pañales", Rad. 13-266923. Resolución de apertura de investigación 47965 de 2014, en http://normograma.info/sic/docs/r_siyc_47965_2014.htm. Resolución de imposición de sanción 43218 de 2016, en http://normograma.info/sic/docs/r_siyc_43218_2016.htm

68 Superintendencia de Industria y Comercio, Caso "Papeles suaves", Rad. 14-151027. Resolución de apertura de investigación 69518 de 2014, en http://normograma.info/sic/docs/r_siyc_69518_2014.htm. Resolución de imposición de sanción 31739 de 2016, en http://normograma.info/sic/docs/r_siyc_31739_2016.htm

69 Superintendencia de Industria y Comercio, Caso "Ruta del Sol", Rad. 17-14777. Resolución de apertura de investigación 67837 de 2018, en http://normograma.info/sic/docs/r_siyc_67837_2018.htm. Caso pendiente de decisión.

70 Como se mencionó, en las que existan al menos dos agentes económicos.

71 Ver tablas contenidas en los anexos 1 y 2 del presente documento.

72 “Desde una perspectiva institucional, la Superintendencia de Industria y Comercio creó el Grupo de Trabajo Interdisciplinario de Colusiones mediante la Resolución 22724 de 18 de abril de 2012, que es un área especializada en el desarrollo de investigaciones para establecer la configuración de esa práctica restrictiva de la competencia en el contexto de la contratación pública. Más adelante, mediante una considerable adición presupuestal que se hizo efectiva en el año 2017 y que estaba destinada a aumentar la capacidad técnica y de personal del área en comento, la Superintendencia la fortaleció y la transformó en el Grupo de Trabajo Élite contra Colusiones" (Gastelbondo Chiriví y Melo Rodríguez, "La colusión: entre las fórmulas verbales y la realidad dinámica", op. cit., pp. 141-179).

73 Si se contrastan los casos en los que se solicitó acceso al programa de beneficios por colaboración con el número de casos que han sido a la fecha decididos la cifra es el 10,3\%. 
de Prácticas Restrictivas de la Competencia, ${ }^{74}$ y de Protección y Promoción de la Competencia, ${ }^{75}$ las investigaciones en las que se ha solicitado acceso al programa de beneficios por colaboración corresponde a un $17,5 \%{ }^{76}$

De acuerdo con el análisis objetivo que a continuación se presenta, pareciera ser que el motivo de la diferencia existente entre el número de solicitudes de acceso al programa de clemencia en procesos de contratación estatal por colusión, de aquellas solicitudes realizadas en procesos por fijación de precios, repartición de mercados y determinación de condiciones de venta del mercado en general, entre otros, radica en el hecho de que, mientras la colusión es un tipo penal, los demás acuerdos restrictivos son sancionados exclusivamente de manera administrativa. En otras palabras, en aquellos casos en los que no existe la posibilidad de enfrentarse a una pena privativa de la libertad, las solicitudes de acceso a los programas de clemencia son mayores. Por el contrario, son menores las solicitudes de acceso a los programas de clemencia cuando, habiendo aceptado la comisión de la conducta anticompetitiva y dotando a la administración de pruebas suficientes para perseguir el cartel empresarial, pueden verse expuestas a sanciones penales que, aun siendo reducidas-como lo establece el parágrafo del artículo 410 A del Código Penal-, desincentivan que un eventual delator se acoja al programa de beneficios por colaboración ofrecido por la Superintendencia de Industria y Comercio.

$\mathrm{Al}$ respecto, debe tenerse en cuenta que, si para ambos casos i) las multas por imponer son las mismas contenidas en los artículos 25 y 26 de la Ley 1340 de 2009 ; ii) los beneficios administrativos a los cuales pueden acceder al suscribir un convenio de colaboración para ambos casos son aquellos contenidos en el Decreto 1523 de 2015; y, adicionalmente, iii) si la autoridad de competencia encargada de investigar ambos casos es la Superintendencia de Industria y Comercio, pareciera ser que el factor diferencial entre las conductas ocurridas en el marco de procesos de contratación estatal, de aquellas que ocurren en el mercado general o privado, se encuentra en el hecho de que mientras la colusión es considerada como un delito, las demás conductas anticompetitivas no lo son.

La conclusión recién anotada cobra sentido si se tiene en cuenta que el motivo por el cual se tipificó la conducta de colusión obedeció a la lucha en contra de la corrupción, ${ }^{77}$ mas no a una lucha en contra de la cartelización empresarial

$74 \quad$ Creado por la Resolución 63211 del 7 de septiembre de 2015, inicialmente organizado y denominado Grupo de Promoción de la Competencia por la Resolución 30578 del 16 de noviembre de 2006.

75 Creado por la Resolución 63208 del 7 de septiembre de 2015, inicialmente organizado y denominado Grupo de Promoción de la Competencia por la Resolución 30578 del 16 de noviembre de 2006.

76 Si se contrastan los casos en los que se solicitó acceso al programa de beneficios por colaboración con el número de casos que han sido decididos a la fecha, la cifra es el 20,5\%.

77 Secretaría de Transparencia de la Presidencia de la República, Estatuto Anticorrupción Ley 1474 de 2011: Avances y desafíos tras cinco años de su expedición, 2016 (Colombia), en http://www.anticorrupcion.gov.co/ Documents/Publicaciones/estatuto-anticorrupcion-ley-1474-2011.pdf 
per se. De allí que sea el único país en América -de aquellos que criminalizan las prácticas restrictivas de la competencia- en el que se cataloga como delito únicamente la colusión en contratación pública y, adicionalmente, que sea el único de estos países en el que no se reduce el $100 \%$ de la sanción penal a la persona que, con ocasión de la suscripción de un convenio de colaboración, se exonere totalmente de la multa administrativa.

Es de anotar que la mayoría de los países de la región conceden beneficios respecto a las sanciones administrativas y penales por imponer a quienes suscriban convenios de colaboración. Lo anterior, bajo el entendido de que han reconocido que si no se ofrecen incentivos reales como la inmunidad penal y administrativa para los infractores del régimen de protección de la libre competencia económica, existirían muy pocos incentivos para delatar. ${ }^{78}$ Por esta razón resulta importante armonizar las políticas criminales con los beneficios por colaboración ofrecidos por la Superintendencia de Industria y Comercio, para generar un aliciente en la participación de personas inmersas en conductas anticompetitivas dentro de este tipo de programas. No debe perderse de vista que la efectividad de las normas del derecho de la libre competencia económica resulta ser menor cuando no se encuentran armonizadas con las normas penales. ${ }^{79}$

Esta situación resulta relevante en la medida en que si no se propende por beneficios que incentiven las solicitudes de acceso a los programas de beneficios por colaboración no se materializarían los fines por los que propende esta figura. Esto dejaría de lado las razones por las cuales se implementó, a saber: i) lograr un incremento en la efectividad de las investigaciones que se adelantan por infracciones al régimen de protección de la libre competencia económica y, por otro lado, ii) facilitar la detección y represión de carteles anticompetitivos a través de la obtención de material probatorio relevante.

Ambas finalidades pueden demostrarse en el caso colombiano. En primer lugar, sobre la efectividad de la que dota este mecanismo a las investigaciones por conductas anticompetitivas, se encuentra que en aquellos casos en los que finalmente se suscribe un acuerdo por colaboración efectivo, los tiempos de investigación se reducen considerablemente.

Un ejemplo preciso de esto puede analizarse a partir de las investigaciones adelantadas en los Grupos de Trabajo de Prácticas Restrictivas de la Competencia, y de Protección y Promoción de la Competencia de la Superintendencia de Industria y Comercio, en los que se investigan conductas anticompetitivas 
que ocurren en el mercado en general o privado. La razón por la que se analiza la duración de las investigaciones que se adelantan en estos grupos de trabajo y no aquella de las adelantadas por el Grupo de Trabajo Élite contra Colusiones -que investiga la colusión en procesos de contratación estatal-, se debe a una sencilla razón. Las dos solicitudes de acceso al programa de beneficios por colaboración -de un total de tres existentes a la fecha en el Grupo de Trabajo Élite contra Colusiones- no fueron exitosas. En efecto, en lo que respecta al caso de Vigilancia, ${ }^{80}$ el delator se retractó de lo dicho y, en el caso de PAE Frutas, ${ }^{81}$ la solicitud de acceso al programa de beneficios por colaboración fue finalmente rechazada por la autoridad de competencia. Puestas de ese modo las cosas, solamente podría analizarse el tiempo de investigación en el caso de la tercera solicitud de clemencia, que corresponde al caso Ruta del Sol. Sin embargo, este caso a la fecha no ha sido sancionado.

Dicho esto, puede observarse que en aquellos casos -adelantados por los Grupos de Trabajo de Prácticas Restrictivas de la Competencia, y de Protección y Promoción de la Competencia de la Superintendencia de Industria y Comercio- en los cuales se han suscrito convenios de colaboración con la autoridad de competencia, los tiempos de investigación son, en promedio, de 18 meses. ${ }^{82}$ Mientras que en aquellos casos en los que no existe una solicitud de acceso a los programas de beneficios por colaboración, el promedio de los tiempos de investigación asciende a 26 meses. ${ }^{83}$ Esto significaría que los tiempos de investigación en los casos en los que existe un delator se reducen en un 30,7 \%.

En segundo lugar, sobre la facilidad que ofrecen los programas de beneficios por colaboración para la detección y represión de los carteles anticompetitivos - a través de la obtención de material probatorio útil- se encontró que, en 9 de los 10 casos existentes, ${ }^{84}$ la solicitud de acceso al programa de beneficios por colaboración se realizó con anterioridad a que se formulara la apertura de investigación y se imputaran cargos. Esto significaría que, casi en la totalidad de los casos, los programas de beneficios por colaboración contribuyeron -en efecto- al propósito de detectar y reprimir carteles empresariales aportando, además, los elementos de prueba suficientes sobre los cuales se fundaron las aperturas de investigación respectivas.

Así, teniendo en cuenta los beneficios de los que dota el programa de clemencia a las investigaciones que adelanta a Superintendencia de Industria y Comercio, debe buscarse una fórmula para incentivar las solicitudes de acceso a los

80 Superintendencia de Industria y Comercio, Caso "Vigilancia", op. cit.

81 Superintendencia de Industria y Comercio, Caso "PAE Frutas", op. cit.

82 Ver tabla contenida en el anexo 2 del presente documento.

83 Idem.

84 El caso de PAE "Frutas" ha sido el único en el que la solicitud de acceso al programa de beneficios por colaboración surgió con posterioridad a la apertura de investigación. Para ese momento de la investigación, los elementos de prueba allegados no cumplieron con el requisito de utilidad de la prueba requerido para ser aceptado dentro del mencionado mecanismo. 
programas de beneficios por colaboración en los casos en los que se investigan acuerdos restrictivos de la libre competencia económica en el marco procesos de contratación estatal. No debe perderse de vista que el hecho de enfrentarse a una pena privativa de la libertad, incluso reducida, como lo propone el parágrafo del artículo 410A del Código Penal colombiano, desincentiva que un eventual delator se acoja al programa de beneficios por colaboración que ofrece la Superintendencia de Industria y Comercio. Es justamente por esta razón que la aplicación del derecho penal como medida de retaliación debería ser de ultima ratio, o, en caso de su aplicación, encontrarse armonizada con las normas que protegen la libre competencia económica, para dotar de efectividad las herramientas con las que cuenta el proceso administrativo sancionador. En otras palabras:

La razón por la que se estima que solo se debe recurrir al Derecho penal cuando, frente a la conducta dañosa de que se trate, ha fracasado el empleo de otros instrumentos sociopolíticos, radica en que el castigo penal pone en peligro la existencia social del afectado, se le sitúa al margen de la sociedad y, con ello, se produce también un daño social. Por todo ello, deben preferirse a las penas todas aquellas medidas que puedan evitar una alteración de la vida en común y que tengan para el afectado consecuencias menos negativas. ${ }^{85}$

Así, tal como se ha analizado hasta este punto, una solución que podría favorecer la efectividad en la aplicación de los programas de beneficios por colaboración, en conductas anticompetitivas que surjan en el marco de procesos de contratación estatal, es eximir de las eventuales sanciones penales a las personas que seas exoneradas del $100 \%$ de la sanción administrativa al acogerse en primer lugar de marcaje a los programas de beneficios por colaboración ofrecidos por la Superintendencia de Industria y Comercio. Esta fórmula es la que ha sido acogida por los países americanos aquí analizados y que guarda una lógica en la aplicación de la figura. Toda vez que la tipificación de prácticas restrictivas de la competencia, como un tipo penal, ha generado -en efecto- un desincentivo en las solicitudes de acceso al programa de beneficios por colaboración ofrecido por la autoridad de competencia. No debe dejarse de lado que este instrumento es una herramienta importante para combatir los carteles empresariales, y el no contemplar la exoneración de las eventuales sanciones penales por la comisión de acuerdos restrictivos de la competencia en contratación estatal priva a la administración pública de estimular el acogimiento de los infractores a los programas de beneficios por colaboración que ofrece. Lo anterior le impide a la Superintendencia de Industria y Comercio obtener, adicionalmente, un ahorro en los tiempos y costos de la detección y represión de la colusión en contratación pública, así como obtener material probatorio contundente que propenda por una mayor efectividad en la lucha contra los carteles empresariales en el mercado.

85 Claus Roxin, Fundamentos político-criminales del Derecho penal, Buenos Aires, Ed. Hammurabi, trad. Córdoba Pastor, 2008, p. 408. 


\section{Conclusiones}

1. Los programas de beneficios por colaboración son una herramienta relevante en la aplicación efectiva de las normas para la protección de la libre competencia económica, al facilitar la detección y represión de carteles empresariales. A través de estos, se propende por incrementar la efectividad de las investigaciones por acuerdos restrictivos de la libre competencia económica, mediante la obtención de material probatorio relevante y la disminución de tiempos de investigación del ente investigador.

2. Países como Chile, Brasil, México, Estados Unidos y Colombia han incrementado las sanciones a fin de hacer más costosa la conducta para el infractor e incentivar con ello las solicitudes de acceso a los programas de beneficios por colaboración.

3. A pesar de que a nivel americano se ha reconocido que una de las formas para incentivar la delación es a través de la concesión de inmunidad penal para los infractores, en el caso colombiano solamente se ha contemplado una reducción de la sanción por imponer. Esto crea una falta de incentivos reales para delatar y acogerse a los programas de beneficios por colaboración que ofrece la Superintendencia de Industria y Comercio y que se encuentran contenidos en el artículo 14 de la Ley 1340 de 2009 y en el Decreto 1523 de 2015.

4. Al protegerse como bien jurídico tutelado, la administración pública -mas no el derecho de la libre competencia económica al momento de tipificar la colusión en contratación pública como un delito- permite que el ejercicio del derecho simbólico en la lucha contra la corrupción subsuma la figura de los programas de beneficios por colaboración.

5. La desconexión entre la política criminal y los beneficios por colaboración en Colombia ha generado un desincentivo en la participación de las personas en los programas de beneficios por colaboración ofrecidos por la Superintendencia de Industria y Comercio, debido a que este mecanismo no incluye la exoneración de las eventuales sanciones penales. De allí que los agentes de mercado incursos en un acuerdo anticompetitivo difícilmente solicitarán acceso a los programas de clemencia -aceptando su comportamiento ilegal-, si con ello solamente se verían beneficiados de la exoneración de la multa administrativa, pero no del riesgo de ir a prisión. Por ello, la tipificación de la colusión como un delito debería incluir la posibilidad para quienes delaten de eximirse de las sanciones penales y administrativas. De otra manera, la figura de la delación como herramienta para combatir la colusión en licitaciones públicas no tendría una mayor aplicación.

\section{Referencias}

Arendt, Hanna, "Responsabilidad personal bajo una dictadura”, en H. Arendt, Responsabilidad y juicio, Barcelona, Paidós Básica, trad. M. Candel, 2007. 
Artaza V., Osvaldo, Matías Belmonte P. y Germán Acevedo M., "El delito de colusión en Chile: propuesta analítica de la conducta prohibida a través de su interpretación como un acuerdo anticompetitivo", Revista Ius et Praxis 24 (2) (2018), pp. 549-592, en https://scielo.conicyt.cl/pdf/iusetp/v24n2/07180012-iusetp-24-02-00549.pdf

Auriol, Emmanuelle, Erling Hjelmeng y Tina Søreide, Deterring corruption and cartels: In search of a coherent approach, Toulouse, Toulouse School of Economics, 2017.

Baker, Donald I, "The use of criminal law remedies to deter and punish cartels and bid-rigging", Geo. Wash. L. Rev. 69 (2001).

Castro Cuenca, Carlos Guillermo, La corrupción pública y privada: causas, efectos y mecanismos para combatirla. Bogotá, D.C., Editorial Universidad del Rosario, 2017. doi: dx.doi.org/10.12804/tj9789587388534.

Código Penal Federal, Última reforma publicada DOF 24-01-2020 (Cámara de Diputados del H. Congreso de la Unión 14 de agosto de 1931), México, en http://www.diputados.gob.mx/LeyesBiblio/pdf/9_240120.pdf

Código Penal Peruano, Decreto Legislativo 635 de 1991 (Modificado por Decreto Legislativo 1034 de 2008 que fue unificado por el Decreto Supremo 030 de 2019), Perú, en http://spij.minjus.gob.pe/content/publicaciones_oficiales/img/CODIGOPENAL.pdf

Corte Constitucional, Sentencia C-032, M. P. Alberto Rojas Ríos, Colombia, 2017, en https://www.corteconstitucional.gov.co/relatoria/2017/c-032-17.htm

Corte Constitucional, Sentencia C-165, M. P. Alejandro Linares Cantillo, Colombia, 2019, en https://www.corteconstitucional.gov.co/ relatoria/2019/C-165-19.htm

Decreto 1074, por medio del cual se expide el Decreto Único Reglamentario del Sector Comercio, Industria y Turismo, Colombia, 2015, en http://www. suin-juriscol.gov.co/viewDocument.asp?id=30019935\#ver_30058124

Decreto 1523, por medio del cual se reglamenta el artículo 14 de la Ley 1340 de 2009 y se modifica el Capítulo 29 del Título 2 de la Parte 2 del Libro 2 del Decreto Único Reglamentario del Sector Comercio, Industria y Turismo, Decreto 1074 de 2015, Colombia, 2015, en http://www.suin-juriscol. gov.co/viewDocument.asp?ruta=Decretos/30019955

Decreto 2896, Por el cual se reglamenta el artículo 14 de la Ley 1340 de 2009, Colombia, 2010, en https://www.sic.gov.co/recursos_user/documentos/ normatividad/Decretos/2010/Deccreto_2896_2010.pdf 
Decreto Ley 211, Por el cual se fijan normas para la defensa de la Libre Competencia, texto redifundido, coordinado y sistematizado por el D.L. 1 de 2004, modificado por la Ley 20.945 de 2016, que perfecciona el sistema de defensa de la libre competencia (Ministerio de Economía, Fomento y Reconstitución 22 de diciembre de 1973), Chile, en https://www.fne.gob.cl/ wp-content/uploads/2010/12/DL_211_refundido_2016.pdf

Decreto Reglamentario 1523, por medio del cual se reglamenta el artículo 14 de la Ley 1340 de 2009 y se modifica el Capítulo 29 del Título 2 de la Parte 2 del Libro 2 del Decreto Único Reglamentario del Sector Comercio, Industria y Turismo, Decreto 1074 de 2015, Colombia, 2015.

Gastelbondo Chiriví, María Catalina y Francisco Melo Rodríguez, "La colusión: entre las fórmulas verbales y la realidad dinámica", en A. M. García Pabón, A. M. Pérez Herrán e I. Beltrán Prado (eds.), Competencia económica: reflexiones sobre los diez años de la Ley 1340 de 2009, Bogotá, Universidad Externado de Colombia, 2019, pp. 141-179, en https://bdigital.uexternado.edu.co/ bitstream/001/2763/1/MGA-spa-2019-La_colusion_entre_las_formulas_ verbales_y_la_realidad_dinamica

Hassemer, Winfried, “Derecho penal simbólico y protección de bienes jurídicos", en Varios Autores Pena y Estado, Santiago, Editorial Jurídica Conosur, 1995, pp. 23-36, en https://perso.unifr.ch/derechopenal/assets/files/obrasportales/op_20130708_01.pdf

Ley 12.529, Estructura el sistema brasileño de defensa de la competencia; prevé la prevención y represión de infracciones contra el orden económico; modifica la Ley 8.137 de 27 de diciembre de 1990, el Decreto Ley 3.689 de 3 de octubre de 1941 y la Ley 7.347 de 1985, Brasil, 2011, en http://www. planalto.gov.br/ccivil_03/_ato2011-2014/2011/lei/112529.htm

Ley 1340, Por medio de la cual se dictan normas en materia de protección de la competencia, Colombia, 2009, en http:/www.secretariasenado.gov.co/ senado/basedoc/ley_1340_2009.html\#33

Ley 8.137, Define delitos contra las relaciones fiscales, económicas y de consumo, y toma otras medidas, Colombia, 1990, en http://www.planalto.gov. br/ccivil_03/LEIS/L8137.htm

Ley Federal de Competencia, Se expide la Ley Federal de Competencia Económica y se reforman y adicionan diversos (Cámara de Diputados del $\mathrm{H}$. Congreso de la Unión), México, 2014, en http://www.diputados.gob.mx/ LeyesBiblio/pdf/LFCE_270117.pdf 
Marvão, Catarina M. P. y Giancarlo Spagnolo, "What Do We Know About the Effectiveness of Leniency Policies? A Survey of the Empirical and Experimental Evidence" (Mimeo), 2014, en https://ssrn.com/abstract=2511613

Montañez Ruiz, Julio César, “Las negociaciones en el proceso penal: del procedimiento inquisitivo a la prisionización masiva", en Revista Derecho Penal y Criminología 34 (97) (2013), pp. 65-83.

Molina Gómez, Juliana, Hacia la implementación de un programa de clemencia en Colombia, Bogotá, Pontificia Universidad Javeriana, 2019, en https://repository.javeriana.edu.co/bitstream/handle/10554/16912/MolinaGomezJuliana2009.pdf?sequence $=1 \&$ isAllowed $=y$

Organization for Economic Co-operation and Development (OECD) (2019), Recommendation of the Council Concerning Effective Action against Hard Core Cartels. OECD/LEGAL/0452, 1-10, en https://legalinstruments.oecd. org/en/instruments/OECD-LEGAL-0452

Organization for Economic Co-operation and Development (OECD), Derecho y Política de la competencia en Colombia, Examen inter-pares (OECD-IDB). Publicaciones de OECD, 2009, pp.1-82, en https://www.oecd.org/countries/ colombia/44111213.pdf

Organization for Economic Co-operation and Development (OECD), Fighting Hard-Core Cartels. OECD Publishing, 2002, pp. 1-102, en https://www. oecd-ilibrary.org/governance/fighting-hard-core-cartels_9789264174993-en

Organization for Economic Co-operation and Development (OECD), Policy Roundtables: Leniency Subsequent Applicants. DAF/COMP(2012)25, 2012, pp. 1-214, en http://www.oecd.org/competition/Leniencyforsubsequentapplicants2012.pdf

Organization for Economic Co-operation and Development (OECD), Ficha informativa sobre los efectos macroeconómicos de la política de competencia, 2014, en http://www.oecd.org/officialdocuments/publicdisplaydocumentpdf/? cote $=\mathrm{DAF} / \mathrm{COMP} / \mathrm{WP} 3(2014) 9 \&$ doclanguage $=$ en

Organization for Economic Co-operation and Development (OECD), Use of Markers in Leniency Programmes. DAF/COMP/WP3(2014)9, 2015, pp. 1-42, en http://www.oecd.org/officialdocuments/publicdisplaydocumentpdf/? cote $=\mathrm{DAF} / \mathrm{COMP} / \mathrm{WP} 3(2014) 9 \&$ doclanguage $=\mathrm{en}$

Organization for Economic Co-operation and Development (OECD), Leniency programmes in Latin America and de Caribbean: Recent experiences and lessons learned in Latin American And Caribbean Competition Forum. DAF/COMP/LACF(2016)5, paper by the Secretariat, Felipe Serrano, 12-13 de abril de 2016, pp. 1-24, en https://one.oecd.org/document/DAF/COMP/ LACF(2016)5/en/pdf 
Organization for Economic Co-operation and Development OECD, Detecting Bid Rigging in Public Procurement: Helping governments to obtain best value for money, s. f., en http://www.oecd.org/competition/cartels/42594486.pdf

Palacios Lleras, Andrés, “La lucha contra los carteles empresariales en la contratación estatal en Colombia", Latin American Law Review 03 (2019), pp. 117-134, https://doi.org/10.29263/lar03.2019.06

Roxin, Claus, Fundamentos político-criminales del Derecho penal, Buenos Aires, Ed. Hammurabi, Buenos Aires, trad. Córdoba Pastor, 2008.

Superintendencia de Industria y Comercio, Informe Motivado, Caso “Papeles Suaves", Rad. 14-151027, Colombia, 2016.

Superintendencia de Industria y Comercio, Informe Motivado, Caso “Vigilancia SIC", Rad. 15-81775, Colombia, 2017.

Superintendencia de Industria y Comercio, Informe Motivado, caso "PAE Frutas", Rad. 17-292981, Colombia, 2018.

Superintendencia de Industria y Comercio, Caso "Vigilancia", Rad. 17-327215. Resolución de apertura de investigación 2065 de 2015, Colombia, en http:// normograma.info/sic/docs/r_siyc_53719_2018.htm

Superintendencia de Industria y Comercio, Caso “Vigilancia”, Rad. 11-71590. Resolución de imposición de sanciones 19890 del 24 de abril de 2017, Colombia, en http://normograma.info/sic/docs/r_siyc_19890_2017.htm

Superintendencia de Industria y Comercio, Caso “PAE Frutas", Rad. 17-292981. Resolución de apertura de investigación 2065 de 2015, Colombia, en http:// normograma.info/sic/docs/pdf/r_siyc_2065_2015.pdf

Superintendencia de Industria y Comercio, Caso “PAE Frutas", Rad. 17-292981, Resolución de imposición de sanciones 71584 del 19 de diciembre de 2019, Colombia, en http://normograma.info/sic/docs/r_siyc_71584_2019.htm

Superintendencia de Industria y Comercio, Caso "Ruta del Sol", Rad. 1714777. Resolución de apertura de investigación 67837 de 2018, Colombia, en http://normograma.info/sic/docs/r_siyc_67837_2018.htm. Caso pendiente por decisión.

Superintendencia de Industria y Comercio, Caso "Papeles suaves", Rad. 14151027. Resolución de apertura de investigación 69518 de 2014, Colombia, en http://normograma.info/sic/docs/r_siyc_69518_2014.htm;

Superintendencia de Industria y Comercio, Caso "Papeles suaves", Rad. 14151027, Resolución de imposición de sanción 31739 de 2016, Colombia, en http://normograma.info/sic/docs/r_siyc_31739_2016.htm 
Superintendencia de Industria y Comercio, Caso "Pañales", Rad. 13-266923. Resolución de apertura de investigación 47965 de 2014, Colombia, en http:// normograma.info/sic/docs/r_siyc_47965_2014.htm.

Superintendencia de Industria y Comercio, Caso "Pañales", Rad. 13-266923, Resolución de imposición de sanción 43218 de 2016, Colombia, en http:// normograma.info/sic/docs/r_siyc_43218_2016.htm

Superintendencia de Industria y Comercio, Caso "Cuadernos", Rad. 14-151036. Resolución de apertura de investigación 7897 de 2015, Colombia, en http:// normograma.info/sic/docs/r_siyc_7897_2015.htm

Superintendencia de Industria y Comercio, Caso "Cuadernos", Rad. 14-151036. Resolución de imposición de sanción 54403 de 2016, Colombia, en http:// normograma.info/sic/docs/r_siyc_54403_2016.htm

Superintendencia de Industria y Comercio, Caso “Tubería”, Rad. 16-453444. Resolución de apertura de investigación 24831 de 2017, Colombia, en http:// normograma.info/sic/docs/r_siyc_24831_2017.htm

Superintendencia de Industria y Comercio, Caso "Tubería”, Rad. 16-453444. Resolución de imposición de sanción 39386 de 2019, Colombia, en http:// normograma.info/sic/docs/r_siyc_39386_2019.htm

Superintendencia de Industria y Comercio, Caso “Cloro Soda”, Rad. 17-288979. Resolución de apertura de investigación 6059 de 2019, Colombia, en http:// normograma.info/sic/docs/pdf/resolucion_superindustria_6059_2019.pdf

Superintendencia de Industria y Comercio, Caso “Cloro Soda”, Rad. 17-288979. Resolución de imposición de sanción 57600 de 2019, Colombia, en http:// normograma.info/sic/docs/r_siyc_57600_2019.htm

Superintendencia de Industria y Comercio, Caso “Boletería”, Rad. 17-327215. Resolución de apertura de investigación 53719 de 2018, Colombia, en http://normograma.info/sic/docs/r_siyc_53719_2018.htm. Caso pendiente por decisión.

Superintendencia de Industria y Comercio, Caso "Mineros", Rad. 14-130744. Resolución de apertura de investigación 53015 de 2016, Colombia, en http://normograma.info/sic/docs/r_siyc_53015_2016.htm. Caso pendiente por decisión.

Superintendencia de Industria y Comercio, Rad. 07-106011, Resolución 64400 de 2011,Colombia, en http://normograma.info/sic/docs/r_siyc_64400_2011.htm 2015, Colombia, en http://normograma.info/sic/docs/r_siyc_91235_2015.htm 
Superintendencia de Industria y Comercio, Rad. 17-329492, Resolución 59363 de 2017, Colombia.

Superintendencia de Industria y Comercio, Rad. 17-335942, Resolución 71843 de 2019, Colombia.

Superintendencia de Industria y Comercio, Caso "INVÍAS", Rad. 17-401804. Resolución de Sanción 73323 del 18 de noviembre de 2020.

Yáñez Rueda, Álvaro, “Balance y desafíos del programa de clemencia en Colombia", en A. M. García Pabón, A. M. Pérez Herrán y I. Beltrán Prado (eds.), Competencia económica: reflexiones sobre los diez años de la Ley 1340 de 2009, Bogotá, Universidad Externado de Colombia, 2019, pp. 181-207. 
Anexo 1. Datos de las investigaciones en procesos de contratación estatal (Colusión)

\begin{tabular}{|c|c|c|c|c|c|c|c|c|}
\hline \multicolumn{9}{|c|}{$\begin{array}{l}\text { Tiempos de investigación sobre acuerdos restrictivos de la competencia en procesos de contratación estatal } \\
\text { (Colusión) }\end{array}$} \\
\hline No. & $\begin{array}{c}\text { Radicado } \\
\text { de la } \\
\text { investigación }\end{array}$ & $\begin{array}{c}\text { Fecha } \\
\text { Resolución } \\
\text { de apertura }\end{array}$ & $\begin{array}{c}\text { Fecha } \\
\text { Resolución } \\
\text { de sanción o } \\
\text { archivo }\end{array}$ & Días & Meses & $\begin{array}{l}\text { Días } \\
\text { que } \\
\text { sobran }\end{array}$ & $\begin{array}{l}\text { Casos con } \\
\text { PBC }\end{array}$ & $\begin{array}{l}\text { Casos } \\
\text { archivados }\end{array}$ \\
\hline 1 & 07-106011 & 24-ago-10 & 16-nov-11 & 449 & 14 & 29 & - & - \\
\hline 2 & 07-103235 & 6-sep-11 & 5-mar-12 & 181 & 6 & 1 & - & $\begin{array}{l}\text { Ordena } \\
\text { archivo }\end{array}$ \\
\hline 3 & $11-60730$ & 7-oct-11 & 9-jul-13 & 641 & 21 & 11 & - & $\begin{array}{l}\text { Ordena } \\
\text { archivo }\end{array}$ \\
\hline 4 & $11-41644$ & 20-sep-11 & 16-sep-13 & 727 & 24 & 7 & - & - \\
\hline 5 & $10-164566$ & 5-may-11 & 9-jul-13 & 796 & 26 & 16 & - & - \\
\hline 6 & $11-46719$ & $3 / 05 / 2011$ & 16-sep-13 & 867 & 28 & 27 & - & - \\
\hline 7 & $11-026754$ & 2-may-11 & 28-jun-12 & 423 & 14 & 3 & - & - \\
\hline 8 & 08-126301 & $23-f e b-11$ & 14-sep-12 & 569 & 18 & 29 & - & - \\
\hline 9 & $12-174085$ & 19-oct-12 & 29-dic-14 & 801 & 26 & 21 & - & - \\
\hline 10 & $11-1329$ & 19-oct-12 & 5-jul-19 & 2.450 & 81 & 20 & - & - \\
\hline 11 & $11-89514$ & 30-mar-12 & 9-sep-13 & 528 & 17 & 18 & - & - \\
\hline 12 & $11-12476$ & 30-mar-12 & 23-nov-18 & 2.429 & 80 & 29 & - & - \\
\hline 13 & $12-236429$ & 16-sep-13 & 24-nov-15 & 799 & 26 & 19 & - & - \\
\hline 14 & $12-227731$ & 27-ago-13 & 16-jun-17 & 1.389 & 46 & 9 & - & - \\
\hline 15 & $12-219725$ & 16-ago-13 & 16-ago-18 & 1.826 & 60 & 26 & - & - \\
\hline 16 & $13-179600$ & 19-mar-14 & 27-ago-15 & 526 & 17 & 16 & - & - \\
\hline 17 & $12-191859$ & 16-dic-15 & 6-jul-17 & 568 & 18 & 28 & - & - \\
\hline 18 & $11-71590$ & 18-ene-15 & 24-abr-17 & 827 & 27 & 17 & $\begin{array}{c}\text { PBC } \\
\text { vigilancia }\end{array}$ & - \\
\hline 19 & $14-32964$ & 20 -oct-16 & 31-ene-19 & 833 & 27 & 23 & - & - \\
\hline 20 & $15-81527$ & 7-feb-16 & 29-ene-19 & 1.087 & 36 & 7 & - & - \\
\hline 21 & $14-92358$ & 9-ago-16 & 13-feb-19 & 918 & 30 & 18 & - & - \\
\hline 22 & $17-292981$ & 1-sep-17 & 9-dic-19 & 829 & 27 & 19 & $\begin{array}{l}\text { PBC PAE } \\
\text { Frutas }\end{array}$ & - \\
\hline 23 & $15-168073$ & 10-jul-17 & 24-dic-19 & 897 & 29 & 27 & - & - \\
\hline 24 & $16-210853$ & 14 -jun-17 & 23-sep-19 & 831 & 27 & 21 & - & - \\
\hline 25 & $15-81775$ & 17-abr-17 & 3-sep-19 & 869 & 28 & 29 & - & - \\
\hline 26 & $17-229681$ & 12-oct-18 & 8-oct-19 & 361 & 12 & 1 & - & - \\
\hline 32 & $17-14777$ & 13-sep-18 & $\begin{array}{l}\text { Pendiente } \\
\text { decisión }\end{array}$ & - & - & - & $\begin{array}{l}\text { PBC Ruta } \\
\text { del Sol }\end{array}$ & - \\
\hline 27 & $16-223755$ & 10-ago-18 & 16-jun-19 & 310 & 10 & 10 & - & $\begin{array}{l}\text { Ordena } \\
\text { archivo }\end{array}$ \\
\hline 30 & $17-048794$ & 5-jul-18 & $\begin{array}{l}\text { Pendiente } \\
\text { decisión }\end{array}$ & - & - & - & - & - \\
\hline
\end{tabular}




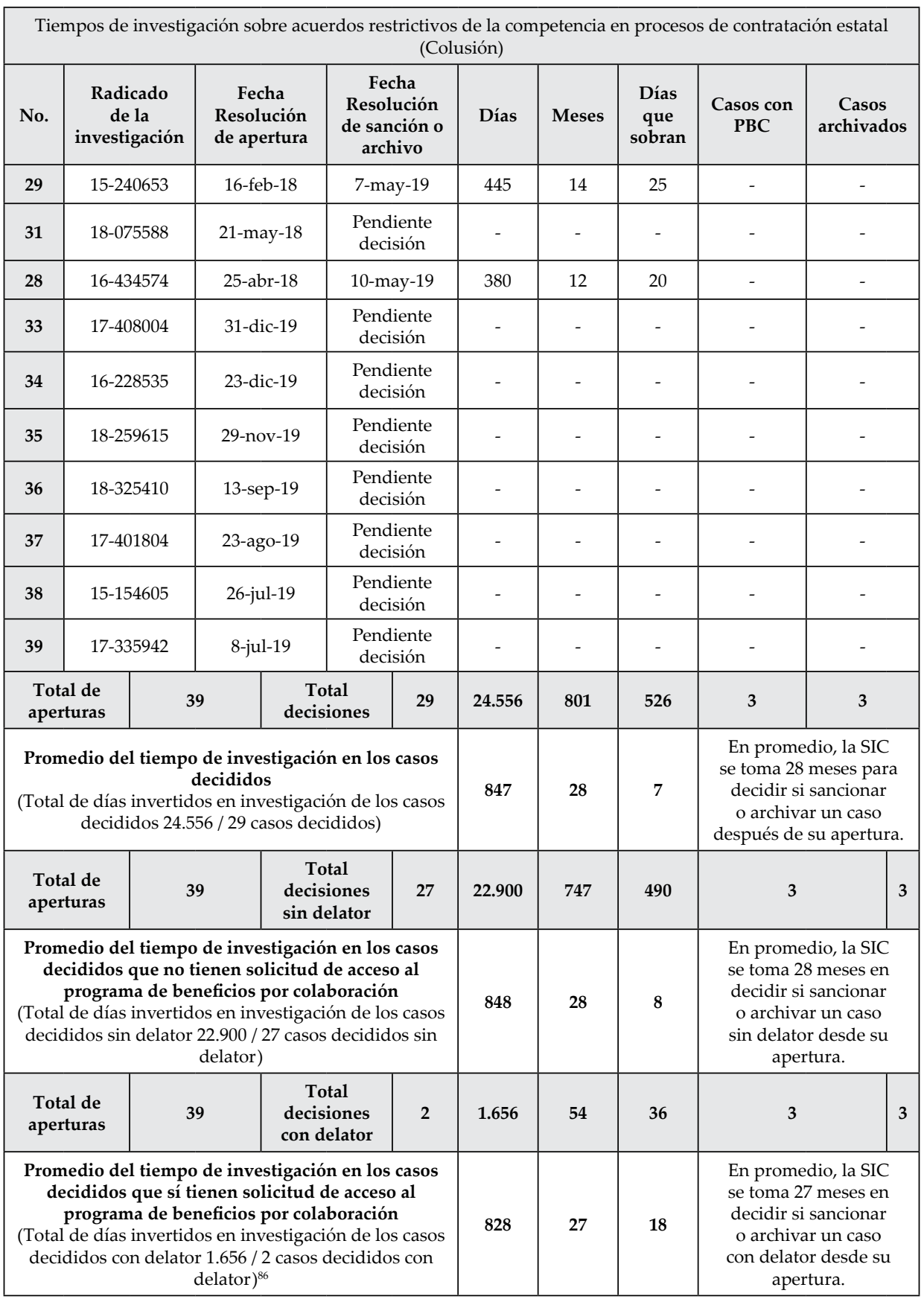

Fuente: elaboración propia a partir de información publicada en el sistema de información Sicomp de la Superintendencia de Industria y Comercio, en https://www.sic.gov.co/sicomp (acceso: 27 de junio de 2020).

$86 \quad$ La inexistencia de una diferencia palpable en el tiempo de investigación obedece a que una de las delaciones fue rechazada y en la segunda hubo retractación. 

Anexo 2. Datos de las investigaciones sobre acuerdos restrictivos de la
competencia en el mercado en general

\begin{tabular}{|c|c|c|c|c|c|c|c|c|}
\hline \multicolumn{9}{|c|}{ Tiempos de investigación sobre acuerdos restrictivos de la competencia en el mercado en general (Privado) } \\
\hline No. & $\begin{array}{c}\text { Radicado } \\
\text { de la } \\
\text { investigación }\end{array}$ & $\begin{array}{c}\text { Fecha } \\
\text { Resolución } \\
\text { de apertura }\end{array}$ & $\begin{array}{c}\text { Fecha } \\
\text { Resolución } \\
\text { de sanción o } \\
\text { archivo }\end{array}$ & Días & Meses & $\begin{array}{l}\text { Días } \\
\text { que } \\
\text { sobran }\end{array}$ & $\begin{array}{c}\text { Casos con } \\
\text { PBC }\end{array}$ & $\begin{array}{c}\text { Casos } \\
\text { archivados }\end{array}$ \\
\hline 1 & $09-021413$ & 6-mar-09 & 30-ago-11 & 907 & 30 & 7 & - & - \\
\hline 2 & 07-091684 & 6-sep-10 & 23-oct-12 & 778 & 25 & 28 & - & $\begin{array}{l}\text { Ordena } \\
\text { archivo }\end{array}$ \\
\hline 3 & $07-027597$ & 30-jun-10 & 12-dic-11 & 530 & 17 & 20 & - & - \\
\hline 4 & 09-007433 & $19-a b r-10$ & 9-mar-12 & 690 & 23 & - & - & - \\
\hline 5 & $09-122453$ & $19-a b r-10$ & 29-abr-11 & 375 & 12 & 15 & - & - \\
\hline 6 & 08-066955 & 28-mar-10 & 6-dic-11 & 618 & 20 & 18 & - & - \\
\hline 7 & 08-078804 & 26-mar-10 & 14-jul-11 & 475 & 15 & 25 & - & - \\
\hline 8 & $08-038436$ & 12 -feb-10 & 21-jun-11 & 494 & 16 & 14 & - & - \\
\hline 9 & $10-165154$ & 30-sep-11 & 27-sep-13 & 728 & 24 & 8 & - & $\begin{array}{l}\text { Ordena } \\
\text { archivo }\end{array}$ \\
\hline 10 & $11-063694$ & 26-ago-11 & 16-dic-14 & 1.208 & 40 & 8 & - & - \\
\hline 11 & $10-67107$ & 22-ago-11 & 27-jun-16 & 1.771 & 59 & 1 & - & $\begin{array}{l}\text { Ordena } \\
\text { archivo }\end{array}$ \\
\hline 12 & $11-001883$ & 20-may-11 & 22-abr-16 & 1.799 & 59 & 29 & - & $\begin{array}{l}\text { Ordena } \\
\text { archivo }\end{array}$ \\
\hline 13 & $10-118560$ & 20-may-11 & 28-jun-12 & 405 & 13 & 15 & - & $\begin{array}{l}\text { Ordena } \\
\text { archivo }\end{array}$ \\
\hline 14 & 08-098094 & 23-mar-11 & 9-may-11 & 47 & 1 & 17 & - & $\begin{array}{l}\text { Ordena } \\
\text { archivo }\end{array}$ \\
\hline 15 & $12-74106$ & 19-oct-12 & 24-jul-15 & 1.008 & 33 & 18 & - & $\begin{array}{l}\text { Ordena } \\
\text { archivo }\end{array}$ \\
\hline 16 & $11-137432$ & 28-sep-12 & 14-abr-15 & 928 & 30 & 28 & - & - \\
\hline 17 & $10-57750$ & 13-feb-12 & 7-oct-15 & 1.332 & 44 & 12 & - & - \\
\hline 18 & $10-83828$ & 29-may-12 & 10-may-16 & 1.442 & 48 & 2 & - & - \\
\hline 19 & $12-061309$ & 11-oct-13 & 10 -feb-17 & 1.218 & 40 & 18 & - & - \\
\hline 20 & $11-116942$ & 21-ago-13 & 11-dic-17 & 1.573 & 52 & 13 & - & - \\
\hline 21 & $12-165930$ & 4-abr-13 & 21-abr-14 & 382 & 12 & 22 & - & - \\
\hline 22 & $12-086114$ & 28-ene-13 & 23-may-16 & 1.211 & 40 & 11 & - & - \\
\hline 23 & $14-151027$ & 24-nov-14 & 26-may-16 & 549 & 18 & 9 & $\begin{array}{c}\text { PBC } \\
\text { Papeles } \\
\text { Suaves }\end{array}$ & - \\
\hline 24 & $13-266923$ & 4-ago-14 & 28-jun-16 & 694 & 23 & 4 & $\begin{array}{c}\text { PBC } \\
\text { Pañales }\end{array}$ & - \\
\hline 25 & $14-151036$ & 27-feb-15 & 18-ago-16 & 538 & 17 & 28 & $\begin{array}{c}\text { PBC } \\
\text { Cuadernos }\end{array}$ & - \\
\hline 26 & $14-130744$ & 10-ago-16 & $\begin{array}{l}\text { Pendiente } \\
\text { decisión }\end{array}$ & - & - & - & $\begin{array}{c}\text { PBC } \\
\text { Mineros }\end{array}$ & - \\
\hline 27 & $12-64145$ & 9-jun-16 & 8-nov-17 & 517 & 17 & 7 & - & - \\
\hline 28 & $17-225744$ & 8-nov-17 & 9-may-19 & 547 & 18 & 7 & - & $\begin{array}{l}\text { Ordena } \\
\text { archivo }\end{array}$ \\
\hline
\end{tabular}




\begin{tabular}{|c|c|c|c|c|c|c|c|c|c|}
\hline \multicolumn{10}{|c|}{ Tiempos de investigación sobre acuerdos restrictivos de la competencia en el mercado en general (Privado) } \\
\hline No. & $\begin{array}{c}\text { Radicado } \\
\text { de la } \\
\text { investigación }\end{array}$ & $\begin{array}{c}\text { Fecha } \\
\text { Resolución } \\
\text { de apertura }\end{array}$ & \multicolumn{2}{|c|}{$\begin{array}{c}\text { Fecha } \\
\text { Resolución } \\
\text { de sanción o } \\
\text { archivo }\end{array}$} & Días & Meses & $\begin{array}{l}\text { Días } \\
\text { que } \\
\text { sobran }\end{array}$ & $\begin{array}{c}\text { Casos con } \\
\text { PBC }\end{array}$ & $\begin{array}{c}\text { Casos } \\
\text { archivados }\end{array}$ \\
\hline 29 & $17-219233$ & 8-nov-17 & \multicolumn{2}{|c|}{ 18-dic-18 } & 405 & 13 & 15 & - & $\begin{array}{l}\text { Ordena } \\
\text { archivo }\end{array}$ \\
\hline 30 & $17-225666$ & 8-nov-17 & \multicolumn{2}{|c|}{ 23-abr-19 } & 531 & 17 & 21 & - & $\begin{array}{l}\text { Ordena } \\
\text { archivo }\end{array}$ \\
\hline 31 & $16-453444$ & 11-may-17 & \multicolumn{2}{|c|}{ 26-ago-19 } & 837 & 27 & 27 & $\begin{array}{c}\text { PBC } \\
\text { Tubería }\end{array}$ & - \\
\hline 32 & $13-103403$ & 14 -feb-17 & \multicolumn{2}{|c|}{ 27-sep-18 } & 590 & 19 & 20 & - & - \\
\hline 33 & $12-160585$ & 13-ago-18 & \multicolumn{2}{|c|}{ 14-dic-18 } & 123 & 4 & 3 & - & - \\
\hline 34 & $17-327215$ & 30-jul-18 & \multicolumn{2}{|c|}{$\begin{array}{l}\text { Pendiente } \\
\text { decisión }\end{array}$} & - & - & - & $\begin{array}{c}\text { PBC } \\
\text { Boletería }\end{array}$ & - \\
\hline 35 & $17-348243$ & 29-nov-19 & \multicolumn{2}{|c|}{$\begin{array}{l}\text { Pendiente } \\
\text { decisión }\end{array}$} & - & - & - & - & - \\
\hline 36 & $17-348260$ & 29-nov-19 & \multicolumn{2}{|c|}{$\begin{array}{l}\text { Pendiente } \\
\text { decisión }\end{array}$} & - & - & - & - & - \\
\hline 37 & $17-348253$ & 29-nov-19 & \multicolumn{2}{|c|}{$\begin{array}{l}\text { Pendiente } \\
\text { decisión }\end{array}$} & - & - & - & - & - \\
\hline 38 & $14-5962$ & 25-jul-19 & \multicolumn{2}{|c|}{ 16-jun-20 } & 327 & 10 & 27 & - & - \\
\hline 39 & $17-2$ & $r-19$ & $28-c$ & $\mathrm{t}-19$ & 224 & 7 & 14 & $\begin{array}{l}\text { PBC Cloro } \\
\text { Soda }\end{array}$ & - \\
\hline 40 & $14-1$ & -19 & $\begin{array}{r}\text { Pen } \\
\text { dec }\end{array}$ & $\begin{array}{l}\text { ente } \\
\text { ión }\end{array}$ & - & - & - & - & - \\
\hline $\begin{array}{l}\text { To } \\
\text { ape }\end{array}$ & $\begin{array}{l}1 \mathrm{de} \\
\text { uras }\end{array}$ & $\begin{array}{r}\text { Tc } \\
\text { decis }\end{array}$ & $\begin{array}{l}\text { al } \\
\text { ones }\end{array}$ & 34 & 24.894 & 813 & 504 & 7 & 10 \\
\hline $\begin{array}{l}\text { Pror } \\
\text { (Tota }\end{array}$ & $\begin{array}{l}\text { edio d } \\
\text { de días } \\
\text { decid }\end{array}$ & $\begin{array}{l}\text { tigacic } \\
\text { estigac } \\
\text { sos dec }\end{array}$ & $\begin{array}{l}\text { en lo } \\
\text { on de l } \\
\text { didos) }\end{array}$ & $\begin{array}{l}\text { casos } \\
\text { casos }\end{array}$ & 732 & 24 & 12 & $\begin{array}{r}\text { En prome } \\
\text { se toma } 24 \\
\text { decidir si } \\
\text { o archiva } \\
\text { después de }\end{array}$ & $\begin{array}{l}\text { lio, la SIC } \\
\text { neses para } \\
\text { sancionar } \\
\text { un caso } \\
\text { u apertura. }\end{array}$ \\
\hline $\begin{array}{l}\text { To } \\
\text { ape }\end{array}$ & $\begin{array}{l}1 \text { de } \\
\text { uras }\end{array}$ & $\begin{array}{r}\mathrm{Tc} \\
\text { decis } \\
\sin \mathrm{d}\end{array}$ & $\begin{array}{l}\text { al } \\
\text { ones } \\
\text { lator }\end{array}$ & 29 & 22.959 & 751 & 429 & 7 & 10 \\
\hline $\begin{array}{r}\text { Pror } \\
\mathbf{d}\end{array}$ & $\begin{array}{l}\text { edio d } \\
\text { ididos } \\
\text { rrograr } \\
\text { de días } \\
\text { idos si }\end{array}$ & $\begin{array}{l}\text { tigaci } \\
\text { icitud } \\
\text { or col } \\
\text { estigac } \\
9 \text { caso }\end{array}$ & $\begin{array}{l}\text { en lo } \\
\text { le acce } \\
\text { oracic } \\
\text { on de l } \\
\text { decidi }\end{array}$ & $\begin{array}{l}\text { casos } \\
\text { al } \\
\text { casos } \\
\text { s sin }\end{array}$ & 792 & 26 & 12 & $\begin{array}{r}\text { En prome } \\
\text { se toma } 26 \\
\text { decidir si } \\
\text { o archiva } \\
\text { sin delato } \\
\text { aper }\end{array}$ & $\begin{array}{l}\text { lio, la SIC } \\
\text { meses en } \\
\text { ancionar } \\
\text { un caso } \\
\text { desde su } \\
\text { ura. }\end{array}$ \\
\hline $\begin{array}{l}\text { To } \\
\text { ape }\end{array}$ & $\begin{array}{l}\text { I de } \\
\text { uras }\end{array}$ & $\begin{array}{r}\text { Tc } \\
\text { decis } \\
\text { con d }\end{array}$ & $\begin{array}{l}\text { al } \\
\text { ones } \\
\text { lator }\end{array}$ & 5 & 2.842 & 92 & 82 & 7 & 10 \\
\hline $\begin{array}{r}\text { Pror } \\
\mathbf{d} \\
\text { (Tota } \\
\text { dec }\end{array}$ & $\begin{array}{l}\text { edio d } \\
\text { ididos } \\
\text { rograr } \\
\text { de días } \\
\text { idos ce }\end{array}$ & $\begin{array}{l}\text { tigacic } \\
\text { icitud } \\
\text { or col } \\
\text { estigac } \\
\text { casos }\end{array}$ & $\begin{array}{l}\text { en lo } \\
\text { e acces } \\
\text { oracic } \\
\text { on de l } \\
\text { ecidid }\end{array}$ & $\begin{array}{l}\text { casos } \\
\text { al } \\
\text { casos } \\
\text { con }\end{array}$ & 568 & 18 & 28 & $\begin{array}{r}\text { En prome } \\
\text { se toma } 18 \\
\text { decidir si } \\
\text { o archiva } \\
\text { con delato } \\
\text { aper }\end{array}$ & $\begin{array}{l}\text { lio, la SIC } \\
\text { meses en } \\
\text { ancionar } \\
\text { un caso } \\
\text { desde su } \\
\text { ura. }\end{array}$ \\
\hline
\end{tabular}

Fuente: elaboración propia a partir de información publicada en el sistema de información Sicomp de la Superintendencia de Industria y Comercio, en https://www.sic.gov.co/sicomp (acceso: 27 de junio de 2020). 